


\section{Effectiveness of iron sludge and fulvic acid for prevention of iron chlorosis in soybean}

Inge Regelink ${ }^{1}$, René Rietra ${ }^{1}$, Rob Comans ${ }^{2}$

1 Wageningen Environmental Research, part of Wageningen University and Research

2 Chairgroup of Soil Chemistry and Chemical Soil Quality, part of Wageningen University and Research

This research was conducted by Wageningen Environmental Research and Wageningen University and received additional funding from TKI Delta Technology under project number WENR16.

Wageningen Environmental Research

Wageningen, November 2019

Reviewed by:

Wim Chardon, Senior Research at Wageningen Environmental Research

Approved for publication:

Gert Jan Reinds, Team Manager Sustainable Soil Use

Report 2971

ISSN 1566-7197 
Regelink, I., R.P.J.J. Rietra and R.N.J. Comans, 2019. Effectiveness of iron sludge and fulvic acid for prevention of iron chlorosis in soybean. Wageningen, Wageningen Environmental Research, Report 2971. 42 pp.; 9 fig.; 12 tab.; 27 ref.

Drinking water company Vitens produces iron sludge and fulvic acid as by-products of their drinking water production process. This study investigated the effectiveness of iron sludge as a source of iron for soybean. A pot experiment was performed with a soybean variety that is susceptible for Fe chlorosis, grown on a clay soil from Tricht (Netherlands) and a calcareous soil from Canaveralejo (Spain). In the Tricht soil, no symptoms of iron chlorosis were observed in any treatment. In the Canaveralejo soil, soybean suffered from iron chlorosis, and iron sludge, with or without fulvic acid, reduced symptoms of iron chlorosis and yield loss as compared to the control treatment. However, iron sludge was not as effective as Fe-HBED since this treatment gave an even higher yield and showed no symptoms of iron chlorosis during the course of the experiment.

IJzerslib en fulvozuren zijn bijproducten van het drinkwaterproductieproces van Vitens B.V. Dit rapport beschrijft de resultaten van onderzoek naar de effectiviteit van ijzerslib, al dan niet gemengd met fulvozuur, als ijzernutriënt voor sojaboon op ijzerdeficiënte gronden. Hiervoor is een potproef uitgevoerd met sojaboon van een soort welke gevoelig is voor ijzerchlorose, geteeld op kleigrond uit Tricht (Nederland) en een kalkgrond uit Canaveralejo (Spanje). In de Tricht grond werd geen ijzergebrek waargenomen bij de sojaboon planten. In de Canaveralejo grond vertoonden sojaplanten wel verschijnselen behorende bij ijzergebrek. Behandeling met ijzerslib, al dan niet met fulvozuur, verminderde de ernst van de gebreksverschijnselen en verhoogde de opbrengst t.o.v. de controle. IJzerslib was echter minder effectief dan de behandeling met Fe-HBED, welke een hogere opbrengst gaf en waarin geen symptomen van ijzerchlorose werd waargenomen.

Keywords: iron chlorosis, iron sludge, soybean, fulvic acid,

The pdf file is free of charge and can be downloaded at https://doi.org/10.18174/503765 or via the website www.wur.nl/environmental-research (scroll down to Publications - Wageningen Environmental Research reports). Wageningen Environmental Research does not deliver printed versions of the Wageningen Environmental Research reports.

2019 Wageningen Environmental Research (an institute under the auspices of the Stichting Wageningen Research), P.O. Box 47, 6700 AA Wageningen, The Netherlands, T +31 (0)317 4807 00, www.wur.nl/environmental-research. Wageningen Environmental Research is part of Wageningen University \& Research.

- Acquisition, duplication and transmission of this publication is permitted with clear acknowledgement of the source.

- Acquisition, duplication and transmission is not permitted for commercial purposes and/or monetary gain.

- Acquisition, duplication and transmission is not permitted of any parts of this publication for which the copyrights clearly rest with other parties and/or are reserved.

Wageningen Environmental Research assumes no liability for any losses resulting from the use of the research results or recommendations in this report.

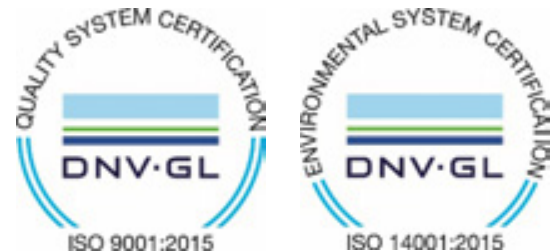

iso $9001: 2015$

In 2003 Wageningen Environmental Research implemented the ISO 9001 certified quality management system.

Since 2006 Wageningen Environmental Research has been working with the ISO 14001 certified environmental care system.

By implementing the ISO 26000 guideline, Wageningen Environmental Research can manage and deliver its social responsibility.

Wageningen Environmental Research report 2971 | ISSN 1566-7197

Photo cover: Soybean plants grown in greenhouse of Wageningen University and Research 


\section{Contents}

$\begin{array}{ll}\text { Verification } & 5\end{array}$

$\begin{array}{ll}\text { Preface } & 7\end{array}$

$\begin{array}{ll}\text { Summary } & 9\end{array}$

1

$\begin{array}{ll}\text { Introduction } & 11\end{array}$

1.1 Iron chlorosis and fertilisation $\quad 11$

1.2 Iron sludge as iron fertiliser $\quad 12$

2

$\begin{array}{ll}\text { Materials and methods } & 13\end{array}$

2.1 Materials and characterisation $\quad 13$

2.1 .1 Iron sludge $\quad 13$

2.1.2 Fulvic acid 14

2.1.3 Synthetic iron fertilisers $\quad 15$

$\begin{array}{ll}2.1 .4 \text { Soils } & 15\end{array}$

2.1.5 Preparation of iron sludge fertilising products 16

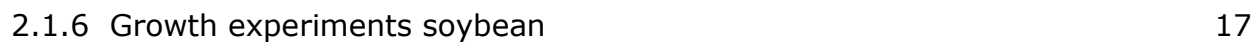

$3 \quad$ Results $r$

$\begin{array}{lll}3.1 & \text { Iron-sludge products } & 20\end{array}$

$\begin{array}{lll}3.2 & \text { Soil Characterisation } & 20\end{array}$

$\begin{array}{lll}3.3 & \text { Results growth experiment - Tricht soil } & 21\end{array}$

$\begin{array}{ll}3.3 .1 \text { Visual observations } & 21\end{array}$

3.3.2 Yield and nutrient content $\quad 22$

$\begin{array}{ll}\text { 3.3.3 Soil analyses } & 22\end{array}$

3.3.4 Extraction of available nutrients: $1 \mathrm{mM}$ versus $10 \mathrm{mM} \mathrm{CaCl} 2$

3.4 Results growth experiment - Canaveralejo soil $\quad 24$

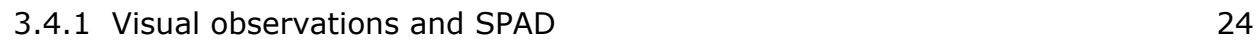

$\begin{array}{ll}3.4 .2 \text { Yield and plant nutrient content } & 27\end{array}$

$\begin{array}{ll}3.4 .3 \text { Soil analyses } & 30\end{array}$

$\begin{array}{lll}3.5 & \text { Discussion } & 31\end{array}$

4

$\begin{array}{ll}\text { Conclusions } & 34\end{array}$

References $\quad 35$

$\begin{array}{lll}\text { Annex } 1 & \text { Raw data soil and plant analyses } & 37\end{array}$ 



\section{Verification}

Report: 2971

Project number: 5200043685

Wageningen Environmental Research (WENR) values the quality of our end products greatly. A review of the reports on scientific quality by a reviewer is a standard part of our quality policy.

Approved reviewer who stated the appraisal,

position: Senior Researcher at Wageningen Environmental Research

name: Wim Chardon

date: $\quad 16-10-2019$

Approved team leader responsible for the contents,

name: Gert Jan Reinds

date: $\quad 29-10-2019$ 


\section{Preface}

This research project was initiated by Vitens B.V., the largest drinking water company of The Netherlands. In The Netherlands, about $60 \%$ of the drinking water originates from groundwater and its purification results in the production of by-products including iron sludge and fulvic acid concentrates. Multiple useful and sustainable applications for iron sludge already exist, including its application as sorbent for the removal of phosphorus in waste water treatment plants or as a reactant to remove sulphur and odours from biogas installations. Nevertheless, Vitens has the ambition to develop new and innovative applications for their iron sludge.

Vitens aims to valorise iron sludge as an iron fertiliser, thereby offering an environmental friendly alternative to synthetic iron fertilisers and creating more economic value from this by-product. In 2015, Vitens started a collaboration with Wageningen University and Research (WUR) in order to investigate the properties of iron sludge and its effectiveness as an iron fertiliser. In that period, chemical analyses and laboratory tests were performed which revealed insights into the nature of iron sludge particles and their behaviour in the presence of fulvic acids, another side stream from the production of drinking water, and its solubility upon addition to soil. These results (Regelink et al., 2018) were promising and the project was therefore continued with additional funding of TKI Deltatechnology in order to test the effectiveness of iron sludge as iron fertiliser in pot experiments. The first pot experiment was performed in 2017 with soil from a Dutch orchard nearby Tricht which was chosen because the pear trees in this orchard showed symptoms of iron chlorosis. In 2018, a second pot experiment was performed with soil collected from Canaveralejo in Spain, a region known for its soils with severe iron deficiency. The results of these two pot experiments are presented in this report.

This research was performed by Wageningen Environmental Research (Inge Regelink, René Rietra) and by the Chair group of Soil Chemistry of Wageningen University (prof. Rob Comans). The authors thank Alexander Laarman and Frank Schoonenberg for initiating the project and their constructive feedback on the results. We thank Joris Wisse of the CAF (Centrale Adviesdienst Fruitteelt) and Mr. Verrips for providing access to their fields in order to collect soil for the pot experiment, Levi Bin of AkzoNobel for providing commercial iron-chelates and dr. R.J. Goos from the department of Soil Science of the North Dakota State University for providing the seeds of a soybean cultivar known to be susceptible to iron chlorosis. Last but not least, we thank Francisco Orgaz from the Instituto de Agricultura Sostenible (Córdoba, Spain) for providing $500 \mathrm{~kg}$ of an iron-deficient soil from the Canaveralejo region. 


\section{Summary}

Iron deficiency is a common problem in areas with alkaline soils. Chelated iron fertilisers, in particular Fe-HBED, are known to be able to prevent symptoms of iron chlorosis in alkaline soils. Iron sludge and fulvic acids are both by-products from drinking water company Vitens and both products may have a positive effect on iron uptake in iron deficient soil.

This study investigated the effectiveness of iron sludge with or without fulvic acid on the prevention of iron chlorosis in soybean. It was also tested if separation of the smallest nano-sized iron particles through addition of a disperging agent (fulvic acid or pyrophosphate) followed by centrifugation provided a product with a higher Fe availability. Iron availability of the iron sludge-based products was assessed using a DTPA extraction, which showed that extractable iron increased in the order: iron sludge $(3-4 \%)<$ iron sludge plus fulvic acid $(12-17 \%)<$ nano-iron plus fulvic acid $(47-50 \%)$.

The effectiveness of iron sludge as iron fertiliser was tested in two pot experiments using a loamy clay soil from Tricht (Netherlands) and a calcareous soil from Canaveralejo (Spain). Soybean plants grown on Tricht soil did not show any symptoms of iron chlorosis during the pot experiment and hence, the results could not be used to draw conclusions about the effectiveness of iron fertilisers on prevention of symptoms of iron chlorosis.

Soybean plants in the control treatment on the Canaveralejo soil showed severe symptoms of iron chlorosis during the first four weeks after sowing. Symptoms of iron chlorosis were less severe in treatments with iron sludge based fertilisers and were absent in the Fe-HBED treatment. Dry matter yield was 30\% higher in treatments with iron sludge-based products (iron sludge, iron sludge plus FA, or nano-iron plus FA). The treatment with Fe-HBED was more effective and led to a $50 \%$ increase in dry matter yield compared to the control. Treatment with Fe-DTPA or fulvic acid did not increase dry matter yield as compared to the control.

Soil analyses showed no significant increase in soluble iron concentrations in pore water or $\mathrm{CaCl}_{2}$ soil extracts except for the Fe-HBED treatment. Iron sludge-based fertilisers increased the Fe-DTPA content of the soil with 0.9 and $2.1 \mathrm{mg} / \mathrm{kg}$ in the Canaveralejo and Tricht soil, respectively and this increase was similar for all tested iron sludge-based fertilisers. Also for Fe-HBED, only a part of the added iron was retrieved in the soil DPTA-extractable fraction, indicating that part of the iron is transformed into other Fe-species insoluble in DTPA.

Fulvic acid (without iron sludge) could not prevent yield losses due to iron chlorosis on the Canaveralejo soil, but did significantly improve phosphate availability and uptake by soybean on the Tricht soil. However, the applied fulvic acid dosage was 7 to 45 times higher than commercially advised product application rates.

Overall, this study shows that iron sludge can reduce yield losses in iron deficient soils but iron sludge is not as effective as Fe-HBED. No differences were observed between the raw iron sludge, mixtures of iron sludge with fulvic acid or the nano-sized fraction of iron sludge with fulvic acid or pyrophosphate. Fulvic acid itself had a positive effect on phosphorus availability and uptake on the Tricht soil. 


\section{Introduction}

\subsection{Iron chlorosis and fertilisation}

Iron chlorosis is a nutritional disorder characterized by a significant decrease of chlorophyll in the leaves and is often observed on alkaline and calcareous soils. It decreases crop yield both quantitatively and qualitatively (Broadley et al., 2012). High soil pH is the most predominant factor explaining the incidence of Fe chlorosis due to the strong decrease in the solubility of Fe(hydr)oxides with increasing $\mathrm{pH}$. A high bicarbonate concentration is another factor that negatively affects iron availability in soils (Boxma, 1972). Iron chelates are used in agriculture and horticulture to prevent symptoms of iron deficiency chlorosis in plants.

Common iron chelates are Fe-DTPA (iron di-ethylene-triamin-penta acetic acid) and Fe-EDDHA (iron ethylene diamine- $\mathrm{N}, \mathrm{N}^{\prime}$-bis(hydroxy phenyl)acetic). Iron-DTPA loses its ability to maintain iron in solution at a $\mathrm{pH}$ above 5 and its application is therefore limited to slightly acidic soils and soilless cultures in greenhouses. Fe-EDDHA is the most effective iron chelate in soils with a neutral or alkaline $\mathrm{pH}$. The effectiveness of Fe-EDDHA as an iron fertiliser has been proven in multiple pot experiments with iron deficient soils (Bin et al., 2016; Schenkeveld et al., 2010) and the application of synthetic iron chelates has become common practice in agriculture. The disadvantage of the excellent capabilities of Fe-chelates in delivering iron to the plants are its poor biodegradation rate and its high affinity for other metals in particular copper and zinc (Schenkeveld et al., 2012).

Iron from natural resources may be an attractive alternative for synthetic iron fertilisers both in terms of environmental impact and economic aspects. Over the last decades, various mineral iron products have been tested on their ability to reduce symptoms of iron chlorosis. These include Fe(II) containing minerals such as vivianite $\left(\mathrm{Fe}_{3}\left(\mathrm{PO}_{4}\right)_{2} \cdot 8\left(\mathrm{H}_{2} \mathrm{O}\right)\right.$ ) (Rosado et al., 2002; Díaz et al., 2010) and $\mathrm{Fe}$ (III) containing minerals such as iron hydroxides and iron carbonate (Vempati \& Loeppert, 1986; Green et al., 1998; Díaz et al., 2009). When applied in soil, these products were found to have a lower efficiency compared to that of iron chelates. For example, field trials with Fe hydroxide minerals showed that its effectiveness is only $10 \%$ when compared to that of Fe-DTPA (Green et al., 1998).

In soilless cultures, promising results were found with iron hydroxides and iron-humic substances (Colombo et al., 2012). Multiple studies have been performed with a so called Fe-WEHS (water extractable humic substances) being a purified humic substance loaded with $\mathrm{Fe}^{3+}$ by means of an ion exchange column (Pinton et al., 1999) leading to formation of iron hydroxide nanoparticles strongly associated with humic substances (Colombo et al., 2012). Various plants, including cucumber, tomato and maize, are able to use iron from such complexes when grown in soilless cultures. However, these products have not been tested in soils and it is thus unknown whether iron-humic complexes are also plant available in alkaline soils where conditions for the formation of poorly insoluble iron hydroxides prevail.

Overall, iron-humic complexes may be valuable iron fertilisers but so far, no commercial applications of iron-humic products as iron fertilisers exist. This may be due to the fact that the previously tested iron-humic products were prepared in the laboratory, meaning that the product is not readily available in large quantities needed to introduce the product to the market. From this perspective, it is of importance to study the iron uptake efficiency of natural iron products that are available in large quantities and at a competitive price. A typical example is iron sludge which is a by-product from drinking water industry. 


\subsection{Iron sludge as iron fertiliser}

Iron sludge is a by-product of the drinking water industry which is formed during the aeration of ironrich anaerobic groundwater. Oxidation of ferrous iron to ferric iron immediately leads to precipitation of iron-hydroxide which is retained in a sand bed. At regular intervals, the sand bed is flushed producing an iron-rich liquid which is subsequently dewatered through settling and addition of flocculants. Previous research on iron sludge from drinking water company Vitens revealed that the product has some interesting and unique characteristics (Regelink et al., 2018). Iron sludge consists of nano-sized iron hydroxide particles clustered into small aggregates with a particle size of several to tens of micrometers. Nanoparticles are known to have a large specific surface area and hence a high capacity to bind ions such as phosphate or humic substances. During the purification process, iron hydroxide particles bind humic substances, most probably fulvic acids since those are known to be present in groundwater. As a result, an iron sludge with about $10 \%$ organic matter (of dry matter) is formed.

It is known that fulvic acids play an important role in the colloidal stability of iron hydroxide particles and hence their mobility in soil (Bollyn et al., 2016). To enhance this effect, additional fulvic acids can be added to the iron sludge. Fulvic acids are another by-product from the drinking water industry. A few drinking water production locations in The Netherlands use groundwater from an aquifer beneath a peat layer and this water has a yellowish colour due the presence of fulvic acids. To remove the colour, fulvic acids are removed through ion exchange producing a concentrated fulvic acid stream as a by-product which is nowadays used as a biostimulant in agriculture and horticulture and as supplement in animal feed. Humic substances, including fulvic acids, are known for their biostimulating properties. Among the multiple claims of humic substances are an increase in the rooting system, nitrogen uptake and plant yield, and an improved resistance against environmental stress factors including drought (Rose et al., 2014).

The effect of fulvic acids on the properties of iron sludge were demonstrated previously using products from drinking water company Vitens. It was found that addition of fulvic acid led to dispersion of iron hydroxide particles. In iron-fulvic acid mixtures containing 2-35 g Fe L-1 and 15-30 g TOC L-1, more than $50 \%$ of the iron was smaller than $0.45 \mu \mathrm{m}$ and could therefore be classified as nanoparticles. In contrast, no iron was present in $0.45 \mu \mathrm{m}$ filtered solutions of iron sludge without additional fulvic acid which was explained by coagulation of iron-hydroxides, forming larger aggregates. The dispersive effect of fulvic acids on iron hydroxides may have important implications for the effectiveness of iron sludge as iron fertiliser since it increases the ability of iron to be transported in soil with soil pore water. It was found that soluble iron concentrations in soil-water suspensions were highly elevated after addition of iron-fulvic mixtures, although this effect was not observed for all tested soils.

The effectiveness of iron sludge as an iron fertiliser depends on whether plants are able to use the iron, and should thus be tested in pot- or field trials under conditions were uptake of iron from soil is limited. We chose to test the effectiveness of iron sludge in pot experiments with soil rather than in soilless cultures because there is a huge market for iron fertilising products that can prevent iron chlorosis on alkaline soils in e.g. Spain, Turkey and Egypt. Moreover, results from soilless cultures cannot be translated to field conditions because the iron uptake efficiency will strongly depend on soilspecific conditions, most typically $\mathrm{pH}$.

This report describes results of two pot experiments in which the effectiveness of iron sludge, with and without additional fulvic acid, on prevention of iron chlorosis in soybean has been tested. Pot experiments were done with a calcareous clay soil collected near Tricht, The Netherlands and a calcareous soil from Canaveralejo, Spain. Both soils were selected because farmers had observed symptoms of iron chlorosis in crops cultivated on these soils. 


\section{$2 \quad$ Materials and methods}

\subsection{Materials and characterisation}

\subsubsection{Iron sludge}

Iron sludge is a by-product from the deferrization of groundwater for the production of drinking water. Liquid iron sludge was sampled at the drinking water production location St. Jansklooster, located in the northern part of The Netherlands. The sludge was allowed to settle to obtain an iron sludge with approximately $0.2-0.3 \%$ dry matter. For each of the two pot experiments, which were executed on a different time, a new batch of iron sludge was sampled. The batches collected in 2017 and 2018 where used for the pot experiments with the Tricht soil and Canaveralejo soil, respectively.

The composition of the iron sludge is given in Table 2.1. The dry matter content of the iron sludge was determined after drying at $105^{\circ} \mathrm{C}$. The chemical composition of the iron sludge was determined after destruction of the fresh material with $\mathrm{HNO}_{3}-\mathrm{HCl}$ (Aqua Regia) followed by analyses of the destruate on $\mathrm{Fe}, \mathrm{Al}, \mathrm{Zn}, \mathrm{Ca}, \mathrm{Mg}, \mathrm{K}, \mathrm{Ni}$ and $\mathrm{Cu}$ using ICP-AES (Varian Vista Pro and ThermoOptek iCAP6500). The organic carbon content was determined on dried sludge samples through combustion using a LECO $\mathrm{C} / \mathrm{N}$ analyser after removal of carbonates with hydrochloric acids.

The availability of iron was assessed through a $0.01 \mathrm{M} \mathrm{CaCl}_{2}$ extraction and a DTPA extraction. To ten grams of iron-suspension $20 \mathrm{ml}$ of the DTPA extracting solution was added. The DTPA extraction solution was prepared according to Lindsay and Norvell (1978). Information on particle size distribution of the iron sludge can be found in a previous report (Regelink et al., 2018).

Table 2.1 Composition of iron sludge per liter product, batch 2017 and 2018

\begin{tabular}{|c|c|c|c|}
\hline & & $\begin{array}{l}\text { Iron sludge } \\
(2017)\end{array}$ & $\begin{array}{l}\text { Iron sludge } \\
(2018)\end{array}$ \\
\hline dry matter & $(\%)$ & 0.6 & 0.7 \\
\hline TOC & (g/kg d.m.) & 106 & n.m. \\
\hline $\mathrm{pH}$ & $(-)$ & 7.5 & 7.8 \\
\hline $\mathrm{Ca}$ & $(\mathrm{mg} / \mathrm{l})$ & 329 & 1219 \\
\hline $\mathrm{Cu}$ & $(\mathrm{mg} / \mathrm{l})$ & $<$ d.l. & $<$ d.I. \\
\hline $\mathrm{Fe}$ & $(\mathrm{mg} / \mathrm{l})$ & 2200 & 3691 \\
\hline $\mathrm{K}$ & $(\mathrm{mg} / \mathrm{l})$ & 4 & 4 \\
\hline $\mathrm{P}$ & $(\mathrm{mg} / \mathrm{l})$ & 49 & 83 \\
\hline $\mathrm{S}$ & $(\mathrm{mg} / \mathrm{l})$ & 14 & 21 \\
\hline As & $(\mu g / I)$ & 603 & n.m. \\
\hline $\mathrm{Cd}$ & $(\mu \mathrm{g} / \mathrm{l})$ & $<$ d.l. & n.m. \\
\hline $\mathrm{Cr}$ & $(\mu \mathrm{g} / \mathrm{l})$ & 148 & n.m. \\
\hline $\mathrm{Ni}$ & $(\mu \mathrm{g} / \mathrm{l})$ & 16 & $\mathrm{n} . \mathrm{m}$ \\
\hline $\mathrm{Pb}$ & $(\mu \mathrm{g} / \mathrm{l})$ & $<$ d.I. & n.m \\
\hline Fe-DTPA & $(\mathrm{mg} / \mathrm{L})$ & 91 & 152 \\
\hline
\end{tabular}




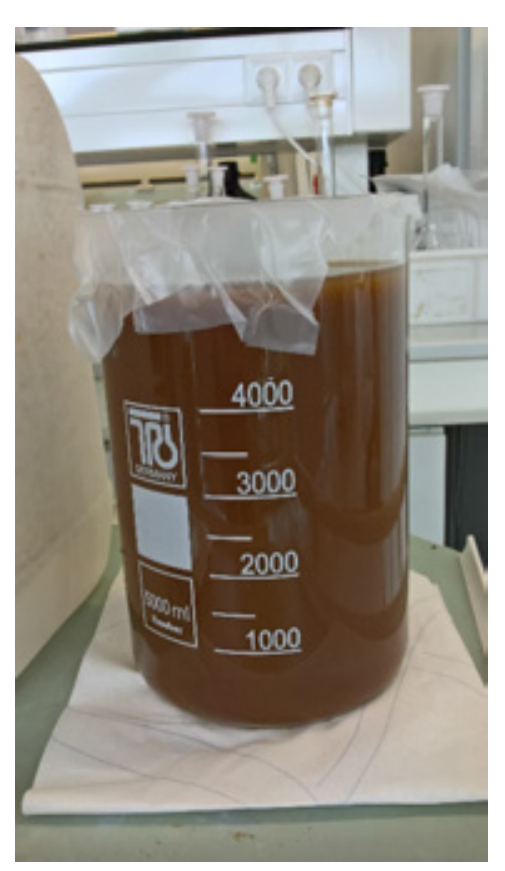

Figure 2.1 Iron sludge used in the experiments

\subsubsection{Fulvic acid}

A $25 \%$ fulvic acid solution was provided by drinking water company Vitens. This company removes fulvic acids from groundwater by ionic exchange because fulvic acids gives the drinkingwater a yellowish colour. The ionic exchange resin is regenerated using $\mathrm{NaCl}$ resulting in the production of a fulvic acid rich stream which is treated by nanofiltration in order to increase the fulvic acid concentration and reduce the salt level. This product is also commercially available as biostimulant under the name HumVi and FulVagra (HuminTech, Germany). The fulvic acid composition is given in Table 2.2.

The chemical composition of the fulvic acid concentrate was determined after destruction with $\mathrm{HNO}_{3}-$ $\mathrm{HCL}$ (Aqua regia). The $\mathrm{N}$-content was determined after destruction with $\mathrm{H}_{2} \mathrm{SO}_{4}-\mathrm{H}_{2} \mathrm{O}_{2}-\mathrm{Se}$ followed by the ortho-P concentration in the destruate using a colorimetric method (Murphy \& Riley, 1962) and a Segmented Flow Analysis (SFA, Skalar) device.

The TOC (total organic carbon) content of the fulvic acid was determined after dilution (500x) followed by analysis of the TOC concentration by means of a Segmented Flow Analysis (SFA) apparatus. The DOC (dissolved organic carbon) concentration was determined after filtration $(0.45 \mu \mathrm{m})$ of the diluted fulvic acid. The diluted and filtered sample was used as a starting point for the fractionation of the organic compounds into humic acids, fulvic acids and hydrophilic acids following the rapid batch approach (van Zomeren \& Comans, 2007). In short, the samples are acidified to $\mathrm{pH} 1$ leading to precipitation of humic acids. After centrifugation, the supernatant is decanted and analysed on DOC (fulvic acids plus hydrophilic acids). Next, a DAX resin is added to the supernatant in order to allow fulvic acids to bind to the DAX resin. After $30 \mathrm{~min}$., the suspension is centrifuged and the supernatant is analysed on DOC (hydrophilic acids). Prior to analyses of the DOC concentration, the $\mathrm{pH}$ of the samples is brought to $\mathrm{pH} \mathrm{6-8} \mathrm{since} \mathrm{the} \mathrm{pH}$ can have an effect on the measurement. The fractionation was performed on 500-times diluted samples since previous tests showed that the fractionation results depend on the initial TOC concentration in the sample. 
Table 2.2 Composition of the fulvic acid concentrate per liter of product ${ }^{1}$

\begin{tabular}{|c|c|c|}
\hline Parameter & Unit & Fulvic acid \\
\hline dry matter & $(\%)$ & 25 \\
\hline Density & $(\mathrm{kg} / \mathrm{L})$ & 1.1 \\
\hline DOC & $(\mathrm{g} / \mathrm{l})$ & 122 \\
\hline $\mathrm{HA}^{\mathrm{b}}$ & $(g / l)$ & 2 \\
\hline $\mathrm{HY} Y^{b}$ & $(g / l)$ & 16 \\
\hline $\mathrm{pH}$ & $(-)$ & 8.3 \\
\hline Al & $(\mathrm{mg} / \mathrm{l})$ & 6 \\
\hline $\mathrm{Ca}$ & $(\mathrm{mg} / \mathrm{l})$ & 635 \\
\hline $\mathrm{Mg}$ & $(\mathrm{mg} / \mathrm{l})$ & 69 \\
\hline $\mathrm{Mn}$ & $(\mathrm{mg} / \mathrm{l})$ & 3 \\
\hline $\mathrm{Na}$ & $(\mathrm{mg} / \mathrm{l})$ & 37440 \\
\hline $\mathrm{P}$ & $(\mathrm{mg} / \mathrm{l})$ & 3 \\
\hline $\mathrm{S}$ & $(\mathrm{mg} / \mathrm{l})$ & 2047 \\
\hline As & $(\mu \mathrm{g} / \mathrm{I})$ & 115 \\
\hline $\mathrm{Cd}$ & $(\mu \mathrm{g} / \mathrm{l})$ & <d.l. \\
\hline $\mathrm{Cr}$ & $(\mu \mathrm{g} / \mathrm{l})$ & 1734 \\
\hline $\mathrm{Ni}$ & $(\mu \mathrm{g} / \mathrm{l})$ & 908 \\
\hline
\end{tabular}

\subsubsection{Synthetic iron fertilisers}

Two synthetic iron chelates salts, an Fe-DTPA (Dissolvine) and Fe-HBED (Bolikel XP), were provided by AkzoNobel. Product composition is given in Table 2.3.

Table 2.3 Composition of the commercial iron chelates ${ }^{1}$

\begin{tabular}{lllllll} 
Commercial name & Type of chelate & Fe-content ( $\%)$ & pH & Formula & Appearance \\
Dissolvine D-Fe-11 & DTPA & $11 \%$ & 2.7 & (DTPA.Fe)H Na & Yellow/green powder \\
\hline Bolikel XP & HBED & $6.1 \%$ & 7 & (HBED.Fe)K & Dark red granules \\
\hline
\end{tabular}

1 Data delivered by AkzoNobel

\subsubsection{Soils}

\section{Tricht}

Two similar pot experiments were performed with two different soils. For the first pot experiment, topsoil (0-20 cm) was collected in May 2017 from an orchard near the village Tricht, in the province Gelderland, the Netherlands. Without Fe fertilisation, the pears (Pyrus communisis L. "conference", rootstock Cydonia oblonga "Kwee $C^{\prime \prime}$ ) cultivated in this orchard show symptoms of iron chlorosis (personal communication J. Wisse from CAF (Centrale Adviesdienst Fruitteelt B.V.)). The soil was airdried and sieved over $8 \mathrm{~mm}$ prior to the pot experiment.

\section{Canaveralejo}

For the second pot experiment, topsoil was collected from an olive orchard near the village Estepa in the province Sevilla location "Canaveralejo", in which experiments have shown iron-deficiency on olivine (Olea europeana "Hoijblanca") (Vega et al., 2008). The soil was air-dried and kindly sent to Wageningen in December 2017 by Dr. F. Orgaz from the Instituto de Agricultura Sostenible (IAS) 
Córdoba (Spain) which is part of the Consejo Superior de Investigaciones Científicas (CSIC). The soil was broken and sieved over $8 \mathrm{~mm}$ in Wageningen.

\section{Soil analyses}

Soil samples were air-dried and ground prior to analysis. The cation exchange capacity (CEC) and exchangeable metals ( $\mathrm{Ca}, \mathrm{Mg}, \mathrm{Na}, \mathrm{K}$, and $\mathrm{Al}$ ) were measured in an unbuffered $\mathrm{BaCl}_{2}$ extract (Houba et al., 1997). Organic matter content was determined by loss-on-ignition. The calcium carbonate content was determined using the volumetric method according to ISO 10693. Total $\mathrm{N}$ was determined after destruction of the soil with $\mathrm{H}_{2} \mathrm{SO}_{4} / \mathrm{H}_{2} \mathrm{O}_{2} / \mathrm{Se}$. The oxalate-extractable $\mathrm{Fe}, \mathrm{Al}, \mathrm{Mn}$ and $\mathrm{P}$ were determined after extraction with acid ammonium oxalate and shaking for two hours in the dark followed by analyses of the $0.45 \mu \mathrm{m}$ filtrates by ICP-AES (Schwertmann, 1964). The phosphorus status of the soil was assessed through extraction with ammonium-lactate (PAL, Houba et al., 1997).

Iron availability was assessed as the DTPA-extractable Fe which was determined after extraction of the soil with a solution of $0.005 \mathrm{M}$ DTPA, $0.1 \mathrm{M}$ TEA (Triethanolamine) and $0.01 \mathrm{M} \mathrm{CaCl}_{2}$ as described by Lindsay and Norvell (1978). After 2 hours shaking, the suspensions were filtered over $0.45 \mu \mathrm{m}$ membrane filters and analysed by ICP-AES on Fe, $\mathrm{Zn}, \mathrm{Cu}$ and $\mathrm{Mn}$.

The easily available elements in soil were measured by extraction with $0.01 \mathrm{M} \mathrm{CaCl}_{2}$ according to Houba et al., (19997) using a 1:10 (w:v) soil-solution ratio. Suspensions were shaken for two hours prior to centrifugation. Extracts were filtered through a $0.45 \mu \mathrm{m}$ membrane filter and the concentrations were measured using ICP-AES.

\subsubsection{Preparation of iron sludge fertilising products}

Four different iron-sludge based products, one fulvic acid and two synthetic iron fertilisers were tested in the pot experiments. The fertilising products were prepared as follows:

\section{Iron sludge (P1)}

Product P1 consist of iron sludge without further treatment. The sludge, which has a dry matter content of about $0.6 \%$, was shaken before being mixed through the soil.

\section{Iron sludge + FA (P2)}

Product P2 was prepared by mixing iron sludge and fulvic acid concentrate at a $80: 20 \mathrm{v} / \mathrm{v}$ ratio and is referred to as Fe-sludge + FA.

\section{Nano-iron + FA (P3)}

Product P3 was prepared by mixing iron sludge and fulvic acid at a 95:5 v/v\% ratio. The suspension was shaken for two hours and thereafter centrifuged at $3000 \mathrm{rpm}$ for $15 \mathrm{~min}$. Thereafter, the supernatant was decanted and used as product P3. Previous work showed that this approach produced an iron-rich solution in which about half of the iron is present as nanoparticles $(<0.45 \mu \mathrm{m})$ (Regelink et al., 2018). This product is therefore referred to as nano-ironFe+FA.

\section{Fulvic acid (P4)}

Fulvic acid concentrate was diluted with demineralised water in a 80:20 (v/v) ratio.

\section{Iron-DTPA (P5) and Fe-HBED (P6)}

Iron-DTPA and Fe-HBED were dissolved in demineralised water to obtain a solution with an iron content of $500 \mathrm{mg} / \mathrm{L}$.

\section{Nano-iron + PP (P7)}

Iron sludge was mixed with a $0.1 \mathrm{M}$ pyrophosphate $\left(\mathrm{Na}_{4} \mathrm{P}_{2} \mathrm{O}_{7}\right)$ solution in a $9: 1 \mathrm{v} / \mathrm{v}$ ratio. The suspension was shaken for two hours and thereafter centrifuged at $3000 \mathrm{rpm}$ for $15 \mathrm{~min}$. The supernatant was decanted and used as iron-product in the pot trial of 2018. This approach resulted in an iron-rich supernatant in which Fe-oxide nanoparticles are stabilized through their interaction with pyrophosphate. 
The iron sludge products were analysed on total Fe and DTPA-extractable Fe content. The TOC content was calculated from the amount of FA added.

\subsubsection{Growth experiments soybean}

\section{Experimental set-up}

Two pot experiments were done. Experiment 1, with the 'Tricht' soil started by sowing seeds on 13 July 2017 and plants were harvested on 7 September 2017. Experiment 2, with the 'Canaveralejo' soil started on 9 April 2018 and ended with the harvest of plants on 28 May 2018. The treatments in both experiments were nearly similar though the precise iron and TOC dosages differed slightly because iron-sludge products were prepared from different batches of iron sludge which slightly differed with respect to iron content.

The soybean seeds (cultivar Mycogen 5072) were kindly provided by dr. R.J. Goos from the department of Soil Science of the North Dakota State University. The seeds were harvested in 2016. This species is known to be susceptible for Fe chlorosis and was also used in previous studies on the effectiveness of synthetic iron chelates (Schenkeveld et al., 2010; Bin et al., 2017).

The pot experiments were carried out in a greenhouse using standard 4.07 liter polypropene pots (Teku item $\mathrm{MCH} 21$-0825) and bottom plates. Macro- and micronutrients were added in similar dosages as reported in Schenkeveld et al. (2008). Each pot received $27 \mathrm{mmol} \mathrm{NH}_{4} \mathrm{NO}_{3}, 17 \mathrm{mmol}$ $\mathrm{K}_{2} \mathrm{PO}_{4}, 13 \mathrm{mmol} \mathrm{CaCl}, 7 \mathrm{mmol} \mathrm{MgSO}, 0.5 \mathrm{mmol} \mathrm{H}_{3} \mathrm{BO}_{3}$ and $0.0025 \mathrm{mmol}\left(\mathrm{NH}_{4}\right)_{6} \mathrm{Mo}_{7} \mathrm{O}_{24}$. Nutrients were dissolved in demi-water and mixed with soil prior to the pot experiment. This fertilisation scheme ensures that all nutrients, except for iron, are available in excess.

The experiment involved testing of iron sludge products, iron fertilisers and fulvic acid according to the dosages given in Table 2.5. For the chelated iron fertilisers (Fe-HBED and Fe-DTPA), an iron dosage of $5 \mathrm{mg} / \mathrm{kg}$ was chosen which is twice the dosage used by Schenkeveld et al., (2010) $(2,6 \mathrm{mg} / \mathrm{kg})$ and roughly twice the commercial application rate (e.g. AgroCentrum; Ferritrac 54, $54 \mathrm{~g} \mathrm{Fe} / \mathrm{L} ; 40 \mathrm{~L} / \mathrm{ha} \approx$ $2 \mathrm{mg} / \mathrm{kg}$ soil). Fe-HBED and Fe-DTPA were delivered as salts. These were used to prepare solutions with an iron content of $500 \mathrm{mg} / \mathrm{L}$ which were subsequently used for application in the pot experiment.

Iron sludge products may have a lower iron availability compared to iron chelates. As such, these products may be needed in a higher total iron dosage in order to obtain a similar effect. As an indicator for Fe-availability, we assessed the DTPA-extractable iron content of the iron-sludge products (Table 3.1) and used this value to determine the product dosage (Table 2.4). For iron sludge without fulvic acid (P1), this approach would lead to an extremely high product dosage since only $3-4 \%$ of the iron was extractable in DTPA. As such, the iron sludge (P1) dosage was set to $30-40 \mathrm{mg} \mathrm{Fe-t/kg} \mathrm{which}$ corresponds to $0.8-0.9 \mathrm{mg} / \mathrm{kg}$ DTPA-extractable Fe.

Iron fertiliser products were thoroughly mixed through the soil to ensure a homogenous distribution. After addition of nutrient solutions and iron sludge products, the moisture content of the soils was made up at approximately $60 \%$ of the water holding capacity. This resulted in $4.4 \mathrm{~kg}$ field-moist soil per pot. The amount of macro-nutrients present in the iron-sludge products $(P, N, K)$ was negligible.

Seeds of soybean were germinated on quartz sand with demineralized water at $20^{\circ} \mathrm{C}$. After 7 days seven seedlings were transferred to each pot which had been filled 4 days before the transfer. The pots were positioned on a table in a greenhouse. Once a day the pots received demineralized water equal to the weight loss due to evapo-transpiration. The pot experiment with the Tricht soil was performed during the summer and hence, no additional light was needed. The pot experiment with the Canaveralejo soil was performed in late-summer and lights were on in order to support growth. No additional micronutrients were added. The temperature in the greenhouse was kept above $20^{\circ} \mathrm{C}$. 
Table 2.4 Treatments in the pot experiment with the Tricht and Canaveralejo soil. All dosages expressed per $\mathrm{kg}$ of soila

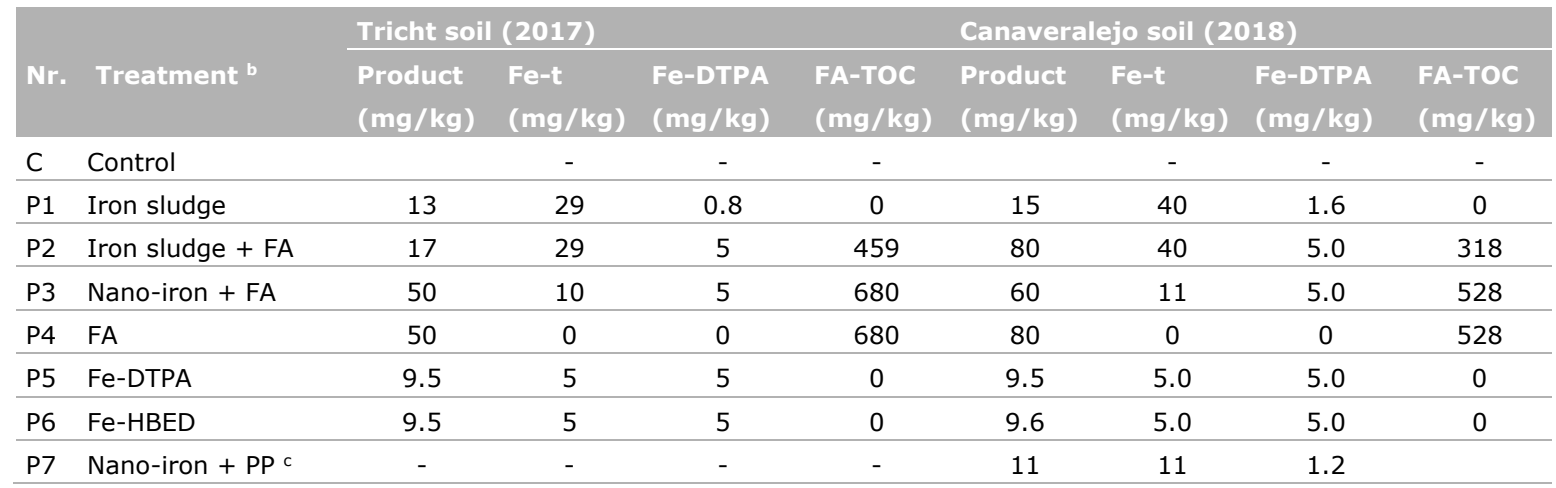

a Product: product dosage in mg/kg soil. Fe-t: total Fe dosage in mg Fe/kg soil, Fe-DTPA: DTPA-extractable Fe dosage in mg Fe-DTPA/kg soil.

FA; fulvic acid dosage in $\mathrm{mg}$ TOC/kg soil in which TOC: Total organic carbon

b Explanation of iron fertilising products see $\S 2.1 .5$

c Product was not included in the experiment with Tricht soil

\section{Sampling and measurement}

\section{Visual observations and SPAD}

Soybean plants were regularly inspected on symptoms of iron chlorosis. Whenever visually detectable differences between plants became apparent, plants were scored on colour and size independently by two employees. SPAD measurements (Minolta-502 SPAD meter) were done twice during the experiment as a measure for leaf chlorophyll concentration. Per pot, SPAD indices were measured for the two youngest leaves and for two leaves from the second youngest trifoliate for all plants.

Measurements were done at the middle section of the leaf, between the central vein and the leaf edge. In the case a leaflet was necrotic, damaged or too small to analyse, no value was recorded. The SPADindices were averaged per pot.

\section{Yield Plant analysis}

At harvest the plants were cut off $2 \mathrm{~cm}$ above the soil surface and the total mass was weighed per pot. Plant parts were dried at $70^{\circ} \mathrm{C}$. After $48 \mathrm{~h}$ the dry weight of the plants was determined. The mineral content was determined using microwave digestion with nitric acid, fluoric acid and hydrogen peroxide. $\mathrm{Cu}, \mathrm{Fe}, \mathrm{K}, \mathrm{Mn}, \mathrm{P}$ and $\mathrm{Zn}$ concentrations were measured on ICP-AES (Varian, Vista pro).

\section{Pore water}

In the Tricht soil, pore water samples were collected and analysed on Fe. At harvest, one kg soil was taken from each pot and centrifuged at $7443 \mathrm{~g}$ for $15 \mathrm{~min}$ (Sorval RC 5C plus) in Delrin (polyacetal) cylindrical 2 compartment containers. The centrifugate was led from the soil-containing compartment over a Whatman 589/3 blue ribbon filter and a Whatman nitrocellulose micropore filter, pore size $0.45 \mu \mathrm{m}$ (WHA10401114), into a soil solution collection compartment. As only a small amount of pore water could be obtained within $15 \mathrm{~min}$, the pore water was diluted with a factor two prior to analysis of its Fe content by ICP-AES.

\section{Soil analysis}

Soil samples were collected from each pot and dried at $40{ }^{\circ} \mathrm{C}$. The $\mathrm{CaCl}_{2}$-extractable nutrients were determined following a standard procedure; however, we used a $1 \mathrm{mM} \mathrm{CaCl}$ extraction solution rather than the standard $10 \mathrm{mM} \mathrm{CaCl} 2$ solution used by commercial laboratories such as Eurofins Agro. A lower $\mathrm{CaCl}_{2}$ concentration was chosen in order to prevent coagulation of iron nanoparticles. For the Tricht soil, part of the samples were also analysed using the standard $10 \mathrm{mM} \mathrm{CaCl}_{2}$ extraction in order to compare the results. The extraction procedure was as follows; $4 \mathrm{gram}$ of dried soil was mixed with $40 \mathrm{~mL} 10 \mathrm{mM} \mathrm{CaCl} 2$ solution and shaken for two hours. The tubes were centrifuged and the supernatant was decanted and filtered over a 0.45 membrane filter. The filtrate was analysed for $\mathrm{Fe}$ $\mathrm{Ca}, \mathrm{Mg}, \mathrm{K}, \mathrm{Na}, \mathrm{P}, \mathrm{Cu}, \mathrm{Zn}$ (ICP-AES), dissolved organic carbon (DOC), total $\mathrm{N}(\mathrm{N}-\mathrm{t}), \mathrm{N}-\mathrm{NO}_{3}$ and $\mathrm{P}-\mathrm{PO}_{4}$ 
(colorimetrically, SFA) and pH. The DTPA-extractable iron content in the soil samples was determined following the approach of Lindsay and Norvell (1978).

\section{Data analyses}

Data were statistically analysed using one way ANOVA for between-treatment differences with Genstat 16th Edition (VSN Int. Ltd.). Soil extractable amounts, nutrient content in plants, plant weight and nutrient uptake by plants were tested using Fisher's protected LSD analysis using a significance level of 0.05 . Each column table gives the probability ( $P$-value)( $F$ pr in Genstat). 


\section{Results}

\subsection{Iron-sludge products}

Table 3.1 gives the total iron content as well as the DTPA-extractable iron of the iron-sludge products. In soil, DTPA-extractable iron is considered as an indicator for Fe-availability. As such, DTPAextractable iron was also determined on the sludge samples in an attempt to assess its available Fe content. Iron sludge (P1) contains about 2.3-3.7 g/L Fe of which only 3-4\% is extractable with DTPA. When mixed with fulvic acid (P2), the total iron content decreases due to dilution whereas the percentage DTPA-extractable iron increases to $12-17 \%$. The effect of fulvic acid on DTPA-extractable iron is likely due to dispersion of iron hydroxide nanoparticles. This effect was also observed in previous tests with iron sludge and fulvic acid (Regelink et al., 2018).

Product P3 consists of the supernatant of iron sludge plus fulvic acid obtained after centrifugation. It thus solely contains small and colloidal stable iron particles. The total iron concentration in this product is low compared to that of the initial iron sludge showing that supernatant contained only $4-9 \%$ of total iron from the sludge. This percentage is much lower than expected since previous tests with iron sludge of this location and two other locations shows that $10-42 \%$ of the iron could be extracted from the sludge with the same procedure. Hence, it may be that the percentage of nanosized iron hydroxides in the sludge that can be extracted after addition of fulvic acids strongly varies per batch. The iron in P3 is for about 50\% extractable in DTPA which is considerably higher than for the P1 and P2 product.

The addition of pyrophosphate had, similar to fulvic acid, a dispersing effect on iron particles. After centrifugation, $0.18 \mathrm{~g} / \mathrm{L}$ Fe remained in the supernatant of which $11 \%$ was DTPA-extractable.

In the pot experiment, the calculated product dosage was based on the DTPA-extractable iron content of the products (Table 3.1).

Table 3.1 Composition of iron-sludge products ${ }^{a}$

\begin{tabular}{|c|c|c|c|c|c|c|c|}
\hline & & \multicolumn{3}{|c|}{ Batch 2017 (Tricht soil) } & \multicolumn{3}{|c|}{ Batch 2018 (Canaveralejo soil) } \\
\hline & & $\begin{array}{l}\text { Fe-t } \\
(g / L)\end{array}$ & $\begin{array}{l}\text { Fe-DTPA } \\
(\% \text { of } F e-t)\end{array}$ & $\begin{array}{l}\text { FA } \\
(g / L)\end{array}$ & $\begin{array}{l}\text { Fe-t } \\
(g / L)\end{array}$ & $\begin{array}{l}\text { Fe-DTPA } \\
\text { ( } \% \text { of Fe-t) }\end{array}$ & $\begin{array}{l}\text { FA } \\
(\mathrm{g} / \mathrm{L})\end{array}$ \\
\hline $\mathrm{P} 2$ & Iron sludge $+F A$ & 1.7 & $17 \%$ & 27 & 2.8 & $12 \%$ & 22 \\
\hline P3 & Nano-iron + FA & 0.2 & $50 \%$ & 14 & 0.13 & $47 \%$ & 6.6 \\
\hline
\end{tabular}

b Fe-t; total Fe in $\mathrm{g} / \mathrm{L}$ product. Fe-DTPA; DTPA-extractable Fe as percentage of total-Fe. FA: fulvic acid expressed as TOC (total organic carbon) in $\mathrm{g} / \mathrm{L}$ and excluding TOC already present in the iron sludge

b Explanation of iron fertilising products see $\$ 2.1 .5$

c Product not used in the experiment with the Tricht soil

\subsection{Soil Characterisation}

Table 3.2 shows the soil characteristics and iron availability as assessed through various analytical measurements. The Canaveralejo soil, collected in Spain, is a calcareous soil consisting for $58 \%$ of calcium carbonate. Iron deficiency is a common problem in calcareous soils due to the combination of a low Fe-content (e.g. determined as Fe-oxalate) and a high $\mathrm{pH}$ which results in a low Fe-availability (e.g. determined as Fe-DTPA or $\mathrm{Fe}-\mathrm{CaCl}_{2}$ ). The Fe-DTPA content of the Canaveralejo soil amounts to $0.9 \mathrm{mg} / \mathrm{kg}$, which is far below the threshold of $5 \mathrm{mg} / \mathrm{kg}$ for iron deficiency (Lindsay \& Norvell, 1978). 
The Tricht soil, a river soil collected in The Netherlands, contains about $4 \%$ calcium carbonate and has a similar pH as the Canaveralejo soil. The Fe-oxalate content, an indicator for the amount of amorphous iron-hydroxides in the soil, is about ten times higher compared to the Canaveralejo soil. Also, the DTPA-extractable iron content is higher and amounts to $40 \mathrm{mg} / \mathrm{kg}$ which is far above the threshold of $5 \mathrm{mg} / \mathrm{kg}$ for iron-deficiency. Hence, no iron deficiency is expected based on these indicators for iron availability. Both soils had a very high $\mathrm{P}$ status.

Table 3.2 General soil characteristics and micronutrient availability in the Tricht and Canaveralejo soil used in the pot experiments

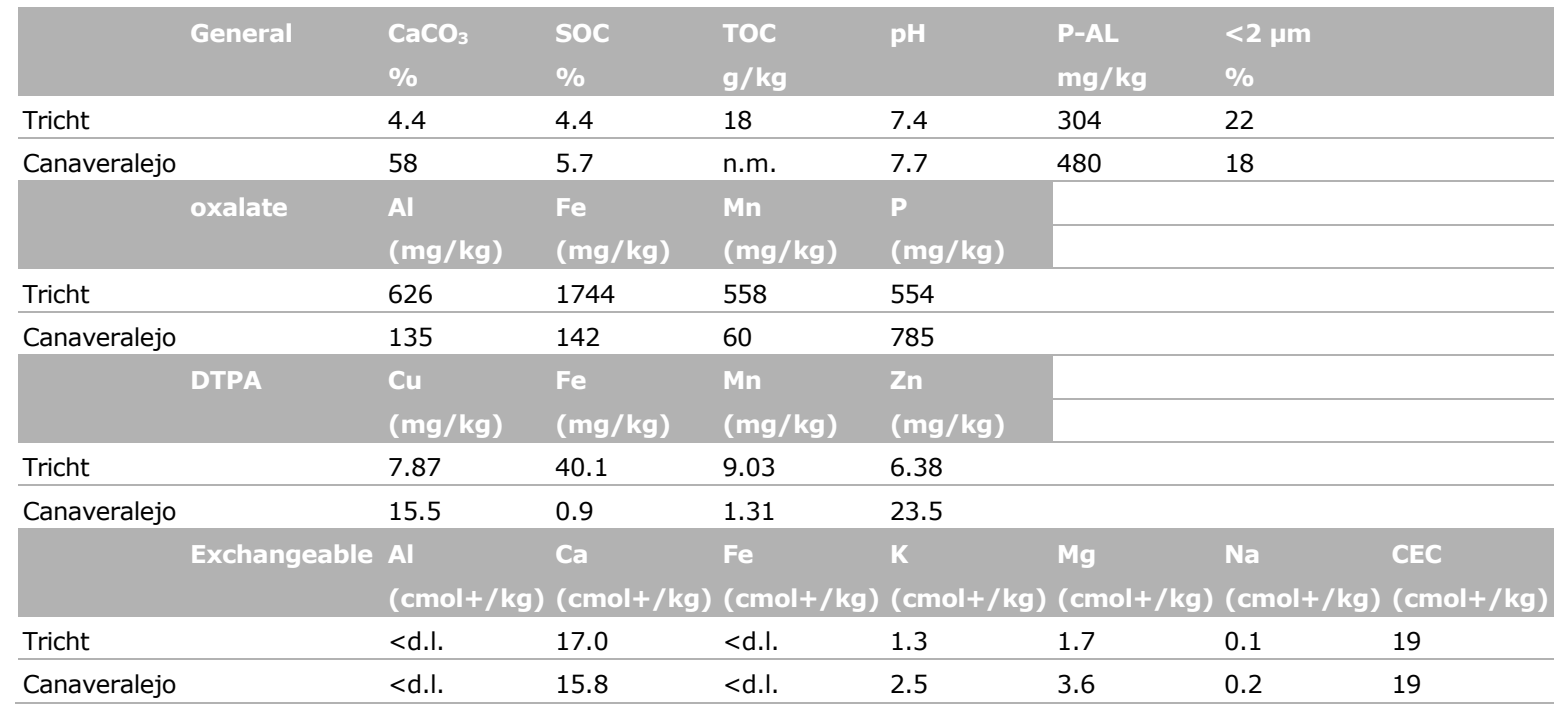

\subsection{Results growth experiment - Tricht soil}

\subsubsection{Visual observations}

During the seven weeks of the growing experiment, plants were regularly inspected on symptoms of iron chlorosis. Typical symptoms are a yellowish colour of the youngest leaves and overall growth reduction. Plants grown on the Tricht soil did not show any visually detectable symptoms of iron chlorosis over the course of the growth experiment (Figure 3.1). In week 4, SPAD measurements of the youngest leaves gave slightly lower values in the control treatment compared to all other treatments (Table 3.3). Though this may indicate chlorosis, the differences were very small and could not be detected visually. It must be noted that SPAD measurements are prone to artefacts due to the fact that leaf colour rapidly changes with leaf age during the first days of leaf development. The researcher decides which leaves are to be considered youngest leaves, second youngest leaves etc., implying that the overall assessment is not fully objective.

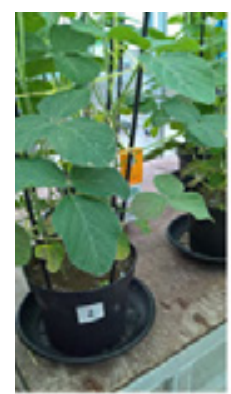

Iron sludge

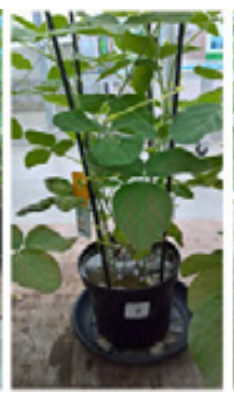

Iron sludge + FA Nano-iron + FA

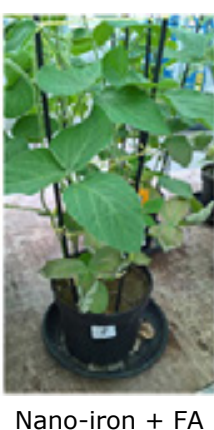

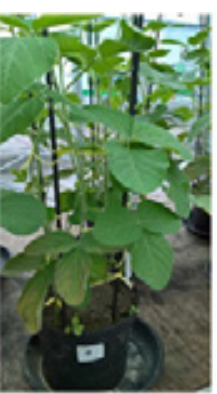

FA

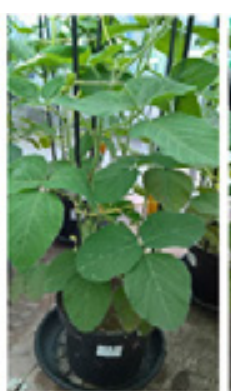

Fe-DTPA

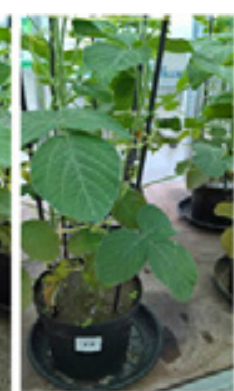

Fe-HBED

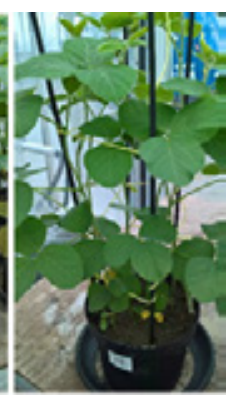

control

Figure 3.1 Photos of soybean grown on Tricht soil without chlorosis (15 Aug 2017, 34 days after sowing) 
Table 3.3 SPAD index of soybean plants measured four and seven weeks after sowing

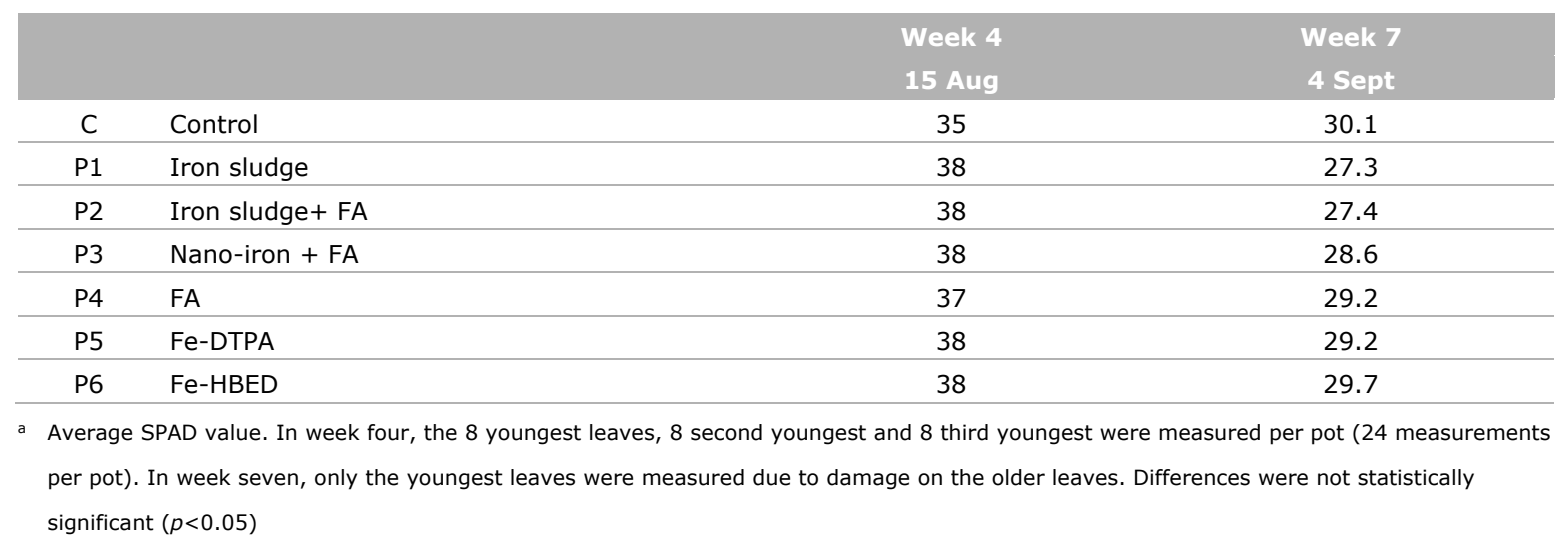

\subsubsection{Yield and nutrient content}

Table 3.4 shows fresh yield, dry matter yield and nutrient content of the soybean plants grown on the Tricht soil after 7.5 weeks (54 days). Differences in plant fresh yield and dry yield between treatments were small and not statistically significant. This result is in line with the fact that no growth reduction or other symptoms of iron chlorosis had been observed during the experiment. Iron content in soybean was lower in pots which received fulvic acid, for all treatments with or without iron sludge (P2, P3, P4). This lower iron uptake efficiency in the presence of fulvic acid was not expected. In the same treatments, phosphorus uptake was elevated. On average, the phosphorus content of soybean increased from $2.6 \mathrm{~g} / \mathrm{kg}$ (control) to $3.5 \mathrm{mg} / \mathrm{kg}$, meaning a $35 \%$ increase in phosphorus uptake in treatments using fulvic acid with or without iron sludge (P2, P3, P4). The higher phosphorus uptake of soybean in the presence of fulvic acid should be considered as 'luxury consumption', i.e. the plant did not need extra phosphorus to support its growth. This is in line with the very high P-status of the soil and the high phosphorus fertiliser dosage. The decrease in iron uptake thus coincides with an increase in phosphorus uptake which may suggest a casual effect. The use of fulvic acids also corresponds with a higher uptake of potassium. This effect is statistically significant for treatment P4 (fulvic acid) but not for the combinations of fulvic acid and iron sludge (P2, P3).

For the micronutrients, some effects of the chelated fertiliser were observed. Manganese uptake was significantly lower in plants treated with Fe-HBED. The use of Fe-DTPA led to a significant increase in zinc uptake which is due to the increased zinc availability in the soil in this treatment (Table 3.5).

Table 3.4 Yield and nutrient content of soybean plants grown on Tricht soil, 7.5 weeks after sowing

\begin{tabular}{|c|c|c|c|c|c|c|c|c|c|}
\hline $\mathrm{Nr}$ & Treatment & $\begin{array}{l}\text { Yield } \\
\text { (g/pot) }\end{array}$ & $\begin{array}{l}\text { Dry yield } \\
\text { (g/pot) }\end{array}$ & $\begin{array}{l}\mathrm{Cu} \\
(\mathrm{mg} / \mathrm{kg})\end{array}$ & $\begin{array}{l}\text { Fe } \\
(\mathrm{mg} / \mathrm{kg})\end{array}$ & $\begin{array}{l}\mathrm{K} \\
(\mathrm{g} / \mathrm{kg})\end{array}$ & $\begin{array}{l}\text { Mn } \\
(\mathrm{mg} / \mathrm{kg})\end{array}$ & $\begin{array}{l}P \\
(g / k g)\end{array}$ & $\begin{array}{l}\mathrm{Zn} \\
(\mathrm{mg} / \mathrm{kg})\end{array}$ \\
\hline $\mathrm{C}$ & Control & 158 & 42 & 8.5 & $55.3 \mathrm{c}$ & $19.3 \mathrm{abc}$ & $63 c$ & $2.65 \mathrm{a}$ & $26.3 \mathrm{a}$ \\
\hline $\mathrm{P} 2$ & Iron sludge+ FA & 162 & 43 & 8.4 & $45.3 \mathrm{ab}$ & $19.9 \mathrm{bcd}$ & $59 \mathrm{c}$ & $3.34 b$ & $29.3 \mathrm{ab}$ \\
\hline P3 & Nano-iron + FA & 168 & 45 & 8.8 & $42.3 \mathrm{a}$ & $20.6 \mathrm{~cd}$ & $60 \mathrm{c}$ & $3.61 b$ & $32.3 \mathrm{~b}$ \\
\hline P5 & Fe-DTPA & 158 & 43 & 9.1 & 52.7 bc & $18.4 \mathrm{ab}$ & $49 b$ & $2.68 a$ & $47 c$ \\
\hline P6 & Fe-HBED & 168 & 46 & 8.0 & $59.3 \mathrm{c}$ & $18.1 \mathrm{ab}$ & $34 \mathrm{a}$ & $2.63 \mathrm{a}$ & $27 a$ \\
\hline & P-value & 0.78 & 0.75 & 0.12 & 0.003 & 0.006 & $<0.001$ & $<0.001$ & $<0.001$ \\
\hline
\end{tabular}

a Different letters within columns denote statistically significant differences between treatments

\subsubsection{Soil analyses}

Table 3.5 shows the results of the soil analyses which were averaged over the three replicated. Raw data are given in Table A2 (Annex 1). 
Iron availability in the soil was assessed through three analyses; iron in pore water, iron extractable in $1 \mathrm{mM} \mathrm{CaCl} 2$ and iron extractable in DTPA. These can be assumed to represent different iron pools in soil going from directly available iron ( $\mathrm{Fe}$-pore water, $\mathrm{Fe}-\mathrm{CaCl}_{2}$ ) to potentially available iron (Fe-DTPA).

Iron concentrations in pore water varied between 0.03 and $0.6 \mathrm{mg} / \mathrm{L}$ between the treatments and iron was significantly higher in soils treated with Fe-DTPA and Fe-HBED. Treatments with iron sludge and fulvic acid (P2, P3, P4, P5) showed slightly higher iron concentrations in pore water but these differences were not statistically significant.

Iron concentrations in $1 \mathrm{mM} \mathrm{CaCl} 2$ were elevated in treatments $\mathrm{P} 3$ (nano-iron + FA) and P4 (FA) both containing fuvic acid. However, iron was not elevated in treatment P2, which also received fulvic acid though in somewhat lower dosage as is also evident from the difference in DOC between treatment P2 and treatments $\mathrm{P} 3$ and $\mathrm{P} 4$. As such, fulvic acid addition is likely to increase $\mathrm{Fe}-\mathrm{CaCl}_{2}$ concentration though only for the highest fulvic acid dosage.

The soil DTPA-extractable iron content increased from $34.6 \mathrm{mg} / \mathrm{kg}$ in the control to 36.7 and $36.6 \mathrm{mg} / \mathrm{kg}$ in the treatments with iron sludge-based products and Fe-HBED, respectively. There were no differences in Fe-DTPA content between treatments. All treatments received an iron dosage corresponding to $5 \mathrm{mg} / \mathrm{kg}$ soil based on the iron fertiliser's DTPA-extractable iron content. Hence, about $40 \%$ of the added iron ended up in the soil Fe-DTPA pool.

Ortho-phosphate concentrations $\left(\mathrm{P}^{-} \mathrm{PO}_{4}\right)$ were significantly higher in soils treated with fulvic acid with and without iron sludge (P2, P3, P4) which corresponds with the elevated phosphorus uptake in these treatments (Table 3.4). Also, concentrations of dissolved organic carbon were highly elevated all treatments with fulvic acid (P2, P3, P4). The same counts for sodium which is higher in the treatments with fulvic acid due to the relatively high sodium content therein.

Table 3.5 Nutrient availability in the soil at the end of the pot trial measured in pore water samples $(\mathrm{mg} / \mathrm{L})$ and in DTPA and $1 \mathrm{mM} \mathrm{CaCl} 2$ soil extracts $(\mathrm{mg} / \mathrm{kg})(n=3)^{a}$

\begin{tabular}{|c|c|c|c|c|c|c|c|c|c|c|c|c|c|}
\hline \multirow[b]{2}{*}{$\mathrm{Nr}$} & \multirow[b]{2}{*}{ Treatment } & \multirow{2}{*}{$\begin{array}{l}\text { Pore water } \\
\text { Fe } \\
(\mathrm{mg} / \mathrm{L})\end{array}$} & \multirow{2}{*}{$\begin{array}{l}\text { DTPA } \\
\text { Fe } \\
(\mathrm{mg} / \mathrm{kg})\end{array}$} & \multicolumn{2}{|c|}{$1 \mathrm{mM} \mathrm{CaCl}_{2}$} & \multirow[b]{2}{*}{ Mg } & \multirow[b]{2}{*}{$\mathrm{Na}$} & \multirow[b]{2}{*}{ P } & \multirow[b]{2}{*}{$\mathrm{Zn}$} & \multirow[b]{2}{*}{ pH } & \multirow[b]{2}{*}{$\mathrm{N}-\mathrm{NO}_{3}$} & \multirow[b]{2}{*}{$\mathrm{P}_{-} \mathrm{PO}_{4}$} & \multirow[b]{2}{*}{ DOC } \\
\hline & & & & $\mathrm{Cu}$ & $\mathrm{Fe}$ & & & & & & & & \\
\hline C & Control & $0.03 a$ & $34.6 \mathrm{a}$ & $0.3 a$ & $7.7 a b$ & 47 & $21 a$ & $10 a$ & $0.1 \mathrm{a}$ & 7.8 & 1.7 & $7.9 a$ & $204 a$ \\
\hline P1 & Iron sludge & $0.05 a b$ & $36.7 b$ & $0.3 a$ & $8.7 a b$ & 43 & $14 a$ & $9.9 \mathrm{a}$ & $0.1 \mathrm{a}$ & 7.8 & 3.4 & $7.8 \mathrm{a}$ & $204 a$ \\
\hline $\mathrm{P} 2$ & Iron sludge $+\mathrm{FA}$ & $0.12 a b$ & $36.7 b$ & $0.4 a b$ & $6.7 \mathrm{a}$ & 41 & $75 \mathrm{~b}$ & $23 b$ & $0.1 \mathrm{a}$ & 7.8 & 3.8 & $20.1 \mathrm{~b}$ & $315 b c$ \\
\hline P3 & Nano-iron + FA & $0.08 a b$ & $36.8 \mathrm{~b}$ & $0.4 \mathrm{~b}$ & $17.3 \mathrm{c}$ & 43 & $125 \mathrm{c}$ & $23 \mathrm{~b}$ & $0.1 \mathrm{a}$ & 7.7 & 3.9 & $19.6 \mathrm{~b}$ & $386 \mathrm{~cd}$ \\
\hline P4 & FA & $0.15 a b$ & $36.2 \mathrm{~b}$ & $0.4 \mathrm{~b}$ & $17.3 \mathrm{c}$ & 47 & $173 c$ & $23 \mathrm{~b}$ & $0.1 \mathrm{a}$ & 7.7 & 3.3 & $19.4 \mathrm{~b}$ & $455 d$ \\
\hline P5 & Fe-DTPA & $0.26 \mathrm{~b}$ & $36.3 \mathrm{~b}$ & $1.2 \mathrm{c}$ & $10.0 \mathrm{ab}$ & 45 & $18 a$ & $12 \mathrm{a}$ & $0.3 \mathrm{~b}$ & 7.8 & 2.0 & $9.3 \mathrm{a}$ & $218 a b$ \\
\hline P6 & Fe-HBED & $0.61 \mathrm{c}$ & $36.6 \mathrm{~b}$ & $0.4 \mathrm{~b}$ & 13.7 bc & 45 & $15 a$ & $12 a$ & $0.1 \mathrm{a}$ & 7.8 & 2.1 & $9.2 \mathrm{a}$ & $243 a b$ \\
\hline & P-value & $<0.001$ & 0.061 & $<0.001$ & 0.014 & 0.155 & $<0.001$ & $<0.001$ & $<0.001$ & 0.003 & 0.093 & $<0.001$ & $<0.001$ \\
\hline
\end{tabular}

a DOC: Dissolved organic carbon. Different letters within columns denote statistically significant differences between treatments

\subsubsection{Extraction of available nutrients: $1 \mathrm{mM}$ versus $10 \mathrm{mM} \mathrm{CaCl} 2$}

Additionally, soil samples of the control, P3 and P4 treatment were also extracted with a $10 \mathrm{mM} \mathrm{CaCl} 2$ solution in order to assess possible differences with the $1 \mathrm{mM} \mathrm{CaCl} 2$ soil extracts. Results are summarized in Table 3.6, which shows the average concentrations of Fe, $\mathrm{P}_{-} \mathrm{PO}_{4}$ and $\mathrm{DOC}$ in the 1 and $10 \mathrm{mM} \mathrm{CaCl} 2$ soil extracts for the three treatments.

Iron concentrations varied between $7.8-17 \mathrm{mg} / \mathrm{kg}$ in the $1 \mathrm{mM} \mathrm{CaCl} 2$ extracts but were all below $0.2 \mathrm{mg} / \mathrm{kg}$ when using a $10 \mathrm{mM} \mathrm{CaCl}$ extraction solution, showing a strong effect of $\mathrm{CaCl}_{2}$ concentration on dispered iron. Since iron concentrations in the $10 \mathrm{mM}$ soil extracts were all near the detection limit of the ICP-AES, a $1 \mathrm{mM} \mathrm{CaCl} 2$ soil extract may be preferred for assessing iron availability. However, in The Netherlands, the $10 \mathrm{mM} \mathrm{CaCl} 2$ is nowadays the standard procedure to 
assess readily available nutrients in soils. The $10 \mathrm{mM} \mathrm{CaCl}$ approach has an important practical advantage; filtration of a $10 \mathrm{mM} \mathrm{CaCl}_{2}$ soil extract over a $0.45 \mu \mathrm{m}$ filter is easy whereas filtration of a $1 \mathrm{mM}$ soil extracts is very difficult and time consuming due to the large concentrations of dispersed colloidal particles.

Phosphate concentrations were also lower when using $10 \mathrm{mM} \mathrm{CaCl}_{2}$ but the differences between the control and the treatments remained. The $\mathrm{CaCl}_{2}$ concentration only had a minor effect on the DOC concentration.

Potassium was measured only in the $10 \mathrm{mM}$ soil extracts. Its concentration is significantly lower in treatments with fulvic acids $(\mathrm{P} 3, \mathrm{P} 4)$ as compared to the control. Potassium is a highly mobile element and its concentration in $\mathrm{CaCl}_{2}$ can be considered as a nearly-total concentration. The lower potassium concentration in treatments with fulvic acid can be partly explained by the higher potassium uptake in those treatments. For the P4 treatment, potassium uptake was $86 \mathrm{mg}$ per pot higher as compared to the control which corresponds to a decrease in the soil potassium content of $20 \mathrm{mg} / \mathrm{kg}$ (each pot contained $4.4 \mathrm{~kg}$ of soil). The higher potassium uptake could thereby explain about $50 \%$ of the observed difference in soil potassium content between the control and P3 treatment, which amounted to $48 \mathrm{mg} / \mathrm{kg}$ as assessed by the $10 \mathrm{mM} \mathrm{CaCl}_{2}$ extract.

Table 3.6 Iron, phosphate and dissolved organic carbon (DOC) in $1 \mathrm{mM}$ and $10 \mathrm{mM}$ soil extracts averaged for three treatments $(n=3)$ expressed in $\mathrm{mg} / \mathrm{kg}$ soil

\begin{tabular}{|c|c|c|c|c|c|c|c|c|}
\hline & \multirow[t]{2}{*}{ Treatment } & \multicolumn{3}{|c|}{$1 \mathrm{mM} \mathrm{CaCl} 2$} & \multicolumn{4}{|c|}{$10 \mathrm{mM} \mathrm{CaCl}_{2}$} \\
\hline & & $\mathrm{Fe}$ & $\mathrm{P}-\mathrm{PO}_{4}$ & DOC & $\mathrm{Fe}$ & $\mathrm{P}-\mathrm{PO}_{4}$ & DOC & K \\
\hline $\mathrm{C}$ & Control & 7.8 & 7.9 & 204 & 0.2 & 6.1 & 190 & 222 \\
\hline P4 & FA & 17.3 & 19.4 & 455 & 0.2 & 14.3 & 423 & 174 \\
\hline
\end{tabular}

\subsection{Results growth experiment - Canaveralejo soil}

\subsubsection{Visual observations and SPAD}

During the seven-week growing experiment, soybean plants were visually inspected on symptoms of iron chlorosis on a regular basis. Figure 3.2 shows a photo of the control and Fe-HBED treatment in order to illustrate the symptoms of iron chlorosis, which are yellow leaves and growth reduction. Figure 3.3 shows one pot with soybean per treatment and allows to compare between treatments. Soybean plants in all treatments, except for Fe-HBED, show clear symptoms of iron chlorosis. Based on these visual observations, no other treatment than Fe-HBED was able to fully prevent iron chlorosis in young soybean plants in the first four weeks after seeding.

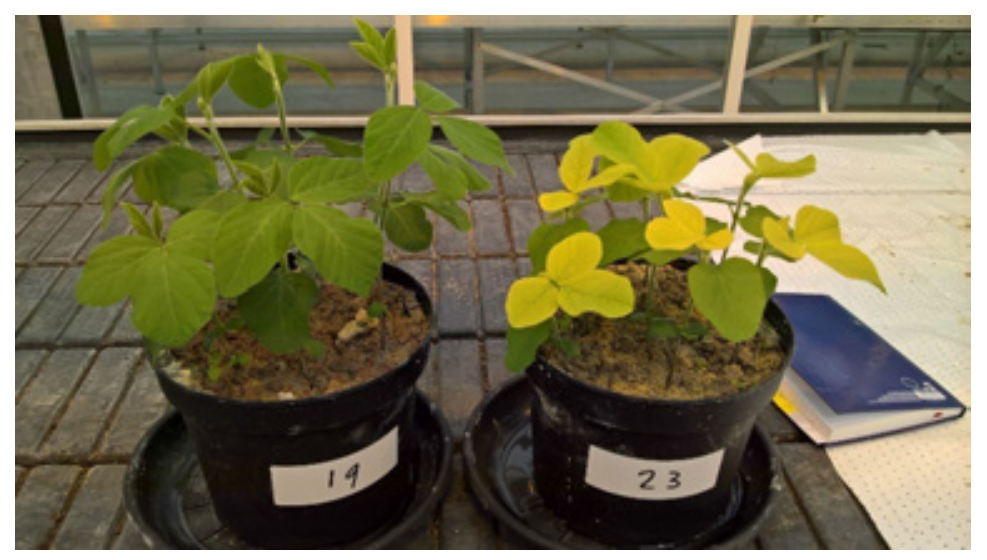

Figure 3.2 Photo of soybean grown on Fe-HBED fertilised soil (left) and the control showing severe effects of iron chlorosis - four weeks after seeding 


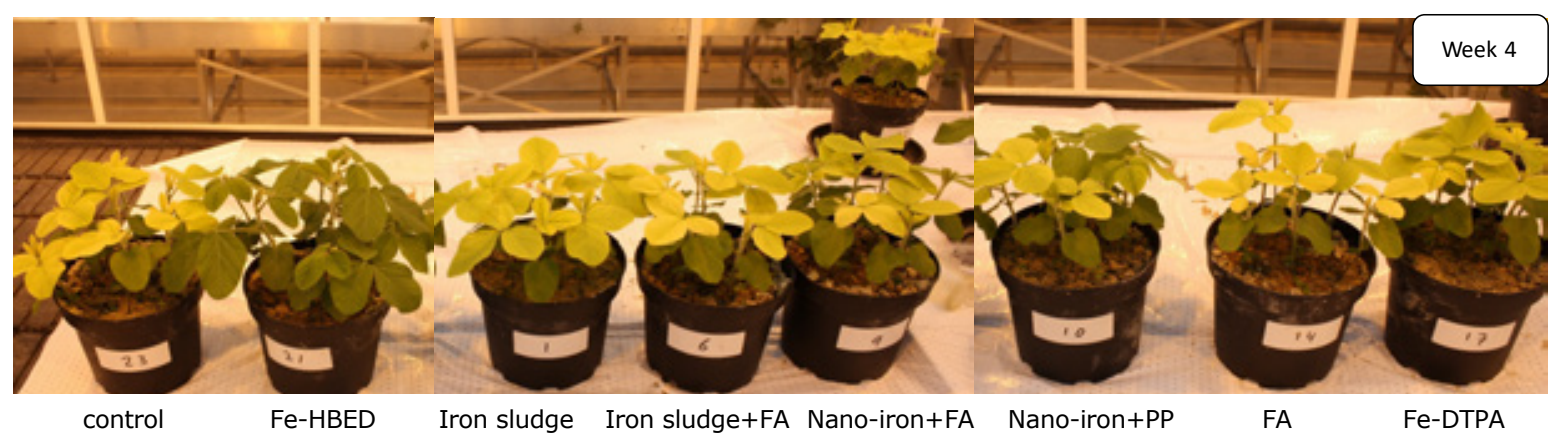

Figure 3.3 Soybean plants four weeks after seeding. The yellowish tint of the photographs is due to the artificial light which was on during the first weeks of the experiment

Figure 3.4 shows one pot for each treatment, five weeks after sowing. Symptoms of iron chlorosis were still evident in the control treatment although the severity of the symptoms rapidly diminished over time.

In order to make a more objective judgement on the severity of iron chlorosis symptoms for each treatment, a semi-quantitative visual judgement was performed. For each pot, the seven youngest leaves were judged on colour (green versus yellow). Figure 3.5 shows the average percentage of yellow leaves per treatment and, using error bars, the percentage of yellow leaves in each individual pot. This evaluation approach shows that all young leaves of soybean in the control treatment were yellowish. Similar, all young leaves of the Fe-DTPA-treated plants were yellow. Soybean plants treated with iron sludge, fulvic acid or a combination of both (P1-P5), received a better score because some of their young leaves were green. Based on this evaluation, there are indications that treatment with iron sludge, and in particular nano-iron (P3, P4), accelerates the recovery of soybean plants from iron chlorosis. However, there is a large variation in the number of yellow leaves between the individual pots and hence, these results must be interpreted with care. It is evident though that no symptoms of iron chlorosis occur in plants treated with Fe-HBED.

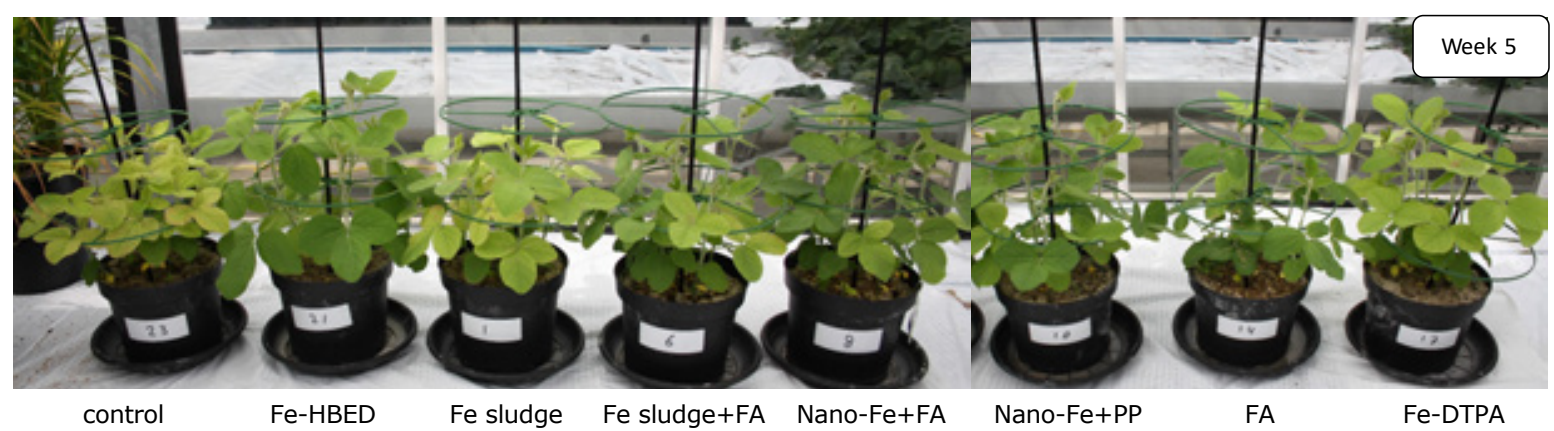

Figure 3.4 Photo of soybean plants, five weeks after sowing 
$\%$ yellow leaves

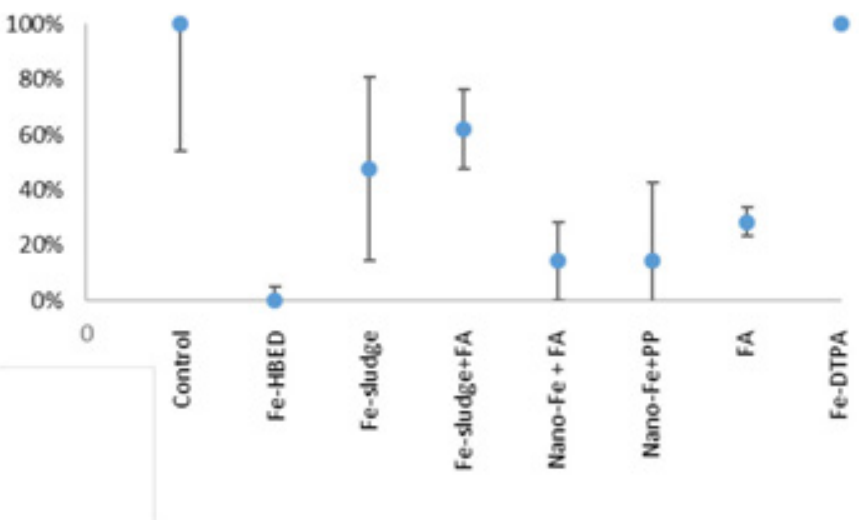

Figure 3.5 Semi-quantitative judgement on iron chlorosis. Percentage of yellow leaves observed in soybean plants visually determined four weeks after sowing. In each pot, the seven youngest leaves were judged on being green or yellow. The figure gives the average and standard deviation of the three replicates i.e. 21 leaves

After seven weeks, it was evident that all plants had recovered from the symptoms of iron chlorosis (Figure 3.6). No visual differences in colour between the treatments could be detected. Therefore, SPAD analyses were performed in order to have a more sensitive measurement of the colour of the youngest and second-youngest leaves which are most prone to iron chlorosis (Figure 3.7). However, also SPAD could not detect any statistically significant differences in leaf colour between treatments and the reference (Fe-HBED). Moreover, there was no difference between the SPAD index in the control plants and chose treated Fe-HBED. It was thus concluded that all soybean plants, regardless whether they had been treated with Fe fertiliser or not, had fully recovered from iron chlorosis.

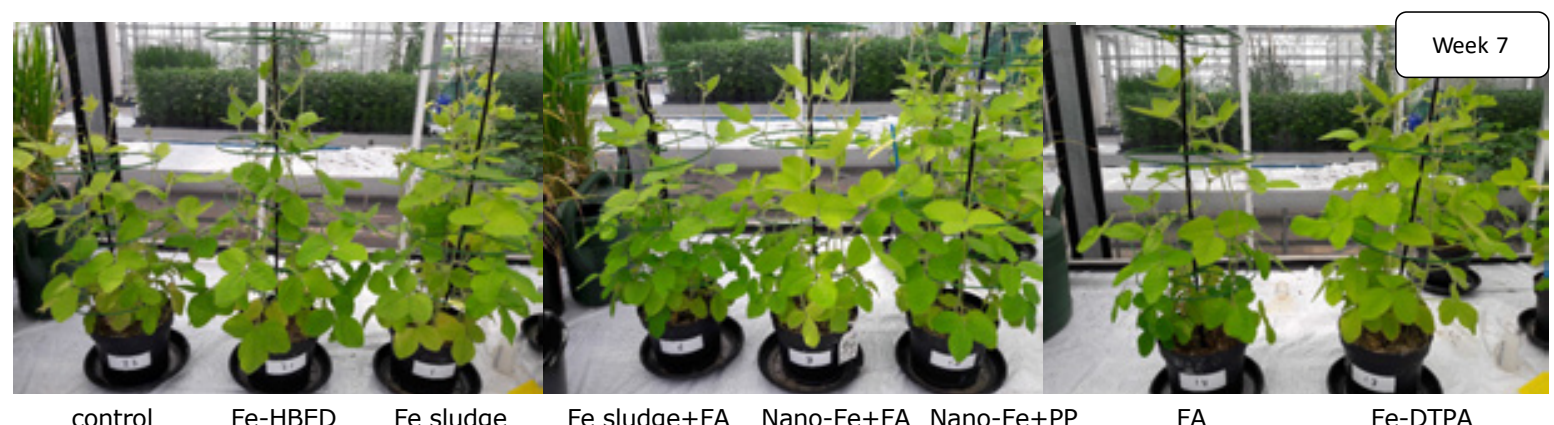

Figure 3.6 Photos of soybean plants seven weeks after sowing 


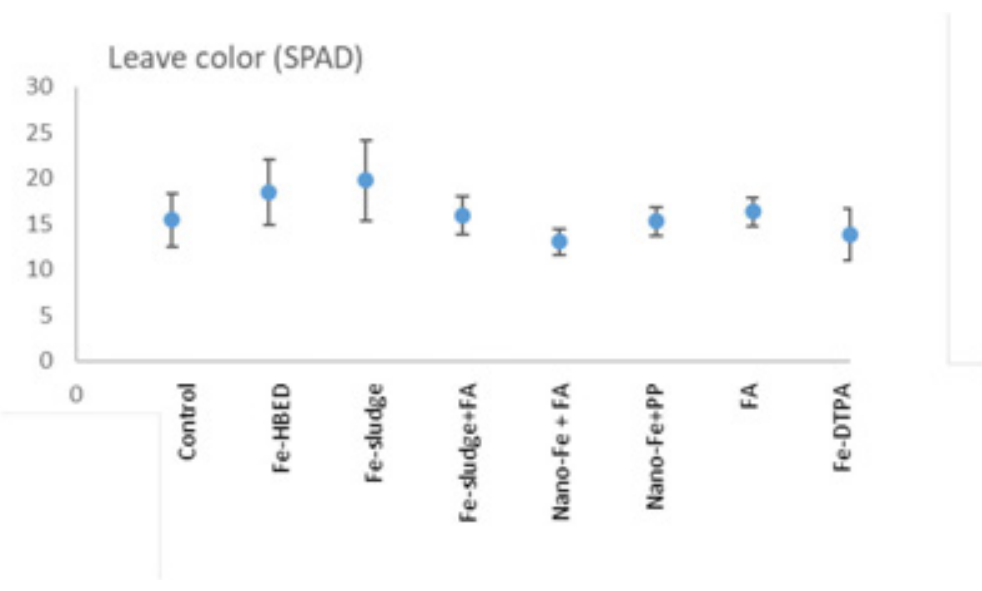

Figure 3.7 Spad-index for different treatments, of the youngest and second youngest leaves, seven weeks after sowing (average and standard deviation of 24 leaves)

\subsubsection{Yield and plant nutrient content}

Table 3.7 shows the plant yield and nutrient content in the soybean plants determined seven weeks after sowing. Raw data are available in Table A3 (Annex 1).

Next to visual observations, plant dry matter yield is considered the most important indicator for iron deficiency. Soybean in the control treatment had a yield of $13.9 \mathrm{gram} /$ pot. Treatment with Fe-DTPA resulted in a similar yield. Treatment with Fe-HBED gave a significantly higher yield of $22.6 \mathrm{~g} / \mathrm{pot}$ which is a $60 \%$ increase compared to the control and Fe-DTPA treatment and thus confirms that iron deficiency caused a severe growth reduction in the control treatment. Treatment with Fe-DTPA however, was not effective in preventing growth reduction in soybean. This confirms that Fe-DTPA is ineffective under alkaline conditions.

Treatment P3 (nano-iron + FA) and P5 (fulvic acids) led to a small increase in dry matter yield compared to the control but this difference was not significant. Treatment with P1 (iron sludge), P2 (iron sludge + FA) and P4 (nano-iron + PP) significantly increased dry matter yield with, on average, $30 \%$ compared to the control.

Iron contents measured in soybean plants appeared to be unreliable since the dataset, consisting of 24 data points, contained fives outliers which values $(51,58,94,98$ and $415 \mathrm{mg} / \mathrm{kg}$ ) were beyond the other data points (average $35 \mathrm{mg} / \mathrm{kg}$ ). Re-analyses of the samples resulted in similar iron contents. Since the iron content correlated well with the aluminium content (Figure 3.8), it was argued that the plant material had become contaminated with dust particles from the soil. A few $\mathrm{mg}$ of soil particles per plant could already have a substantial effect on iron and aluminium measurements. In a following experiment, we advise to wash plant material thoroughly with demineralised water in order to prevent contamination from soil particles.

It was decided to exclude values of $51 \mathrm{mg} / \mathrm{kg}$ and above $(n=5)$ and to perform further statistical analysis on the remaining values $(n=19)$. Table 3.6 gives the average values excluding outliers. The raw data, including outliers, is available in Table A3 (Annex 1). For the treatment with iron sludge, none of the measurements was below $51 \mathrm{mg} / \mathrm{kg}$ and hence no value is given. Iron content in soybean was not significantly different between treatments. Iron uptake per pot was higher in the Fe-HBED treatment as compared to the FA treatment. Hence, the effects of iron chlorosis observed during the first weeks of the pot experiment were not reflected in the iron content of the plants. This may be due to the fact that the iron deficient plants were able to restore their iron content during the last weeks of the experiment. 


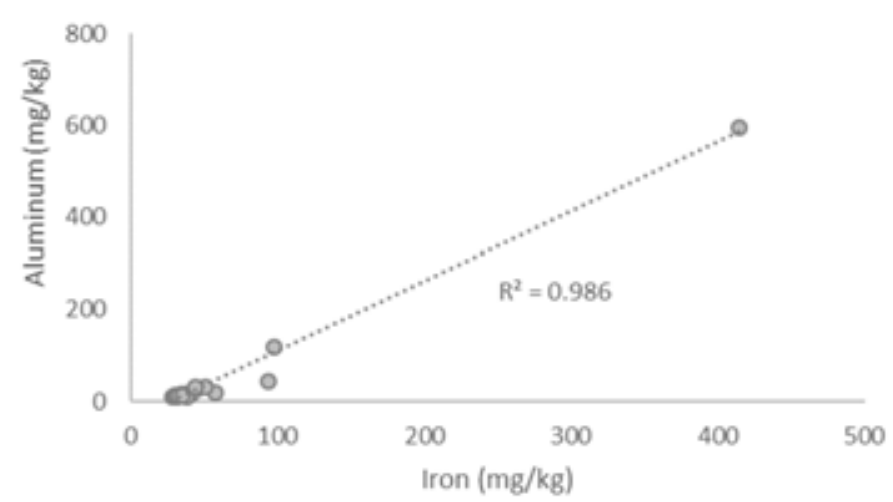

Figure 3.8 Correlation between iron and aluminium in soybean ( $\mathrm{mg} / \mathrm{kg} \mathrm{dw}$ ) showing a correlation between outliers for iron and aluminium

The phosphorus contents in soybean plants was slightly lower in the treatment with iron sludge (P1). Although iron sludge acts as a sorbent for phosphorus, the P sorption capacity of the applied iron sludge is small compared to overall $P$ content of the soil and not expected to affect $P$ availability. This is confirmed by the soil analyses in which there is no difference between phosphate between the two treatments. Hence, there is no explanation for the lower phosphorus content. In the Canaveralejo soil, fulvic acid did not affect phosphorus uptake whereas this was the case in the Tricht soil.

Soybean plants grown on soils treated with fulvic acid containing products (P2, P3, P5) had lower contents of cations including $\mathrm{Cu}, \mathrm{Ca}, \mathrm{K}, \mathrm{Mg}$ and $\mathrm{Mn}$. These differences were statistically significant for treatments with fulvic acid (P5) and nano-iron + FA (P4), except for the cation Ca. The cation contents are strongly correlated to one another suggesting that one single process determines the plant contents of these various cations. For example, the following correlations were found: $\mathrm{Cu}$ and $\mathrm{Mg}$ $\left(R^{2}=0.76\right), \mathrm{K}$ and $\mathrm{Mg}\left(\mathrm{R}^{2}=0.79\right), \mathrm{Mn}$ and $\mathrm{Mg}\left(\mathrm{R}^{2}=0.90\right), \mathrm{Ca}$ and $\mathrm{Mg}\left(\mathrm{R}^{2}=0.70\right)$, and $\mathrm{Zn}$ and $\mathrm{Mg}$ $\left(R^{2}=0.90\right)$. Apparently, uptake of these cations is hampered in the presence of high concentrations of fulvic acid.

Copper and zinc uptake were not higher in soybean grown on Fe-DTPA treated soils (Table 3.7), despite the fact that the concentrations of these elements in the soil extracts were substantially higher than the control (Table 3.5). 


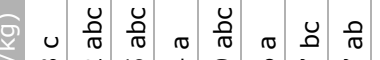

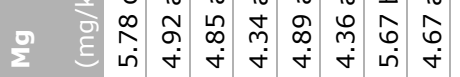

$\ddot{8}$

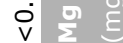

先

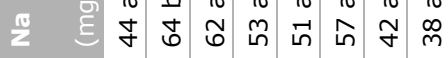

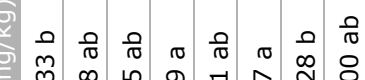

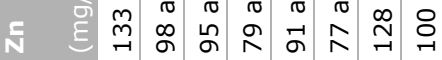

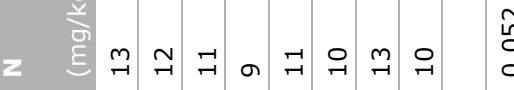

$\frac{2}{\frac{2}{8}}$

$\overrightarrow{0}$

$\delta$

క

齐

in

to

¿

ఏ

章

$\frac{\sqrt{2}}{\frac{\pi}{2}}$

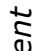

$\stackrel{5}{\stackrel{5}{5}}$

ำ

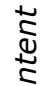

ठั

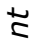

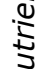

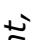

志

3

궁

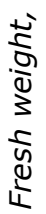

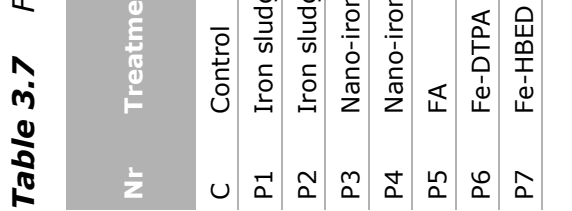

$\underset{0}{20}=\frac{10}{2}$

홍

กูก

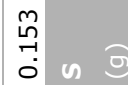

केष

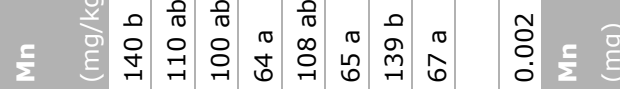

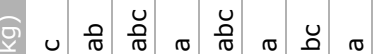

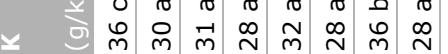

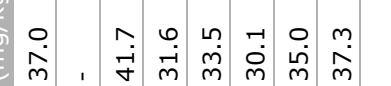

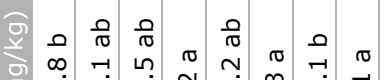

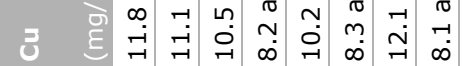

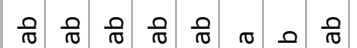

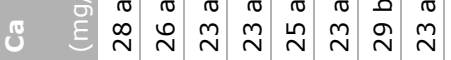

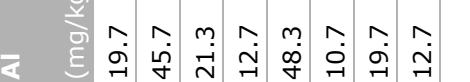

글

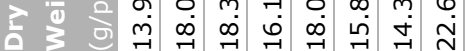

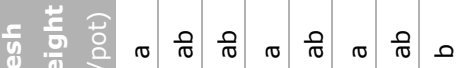

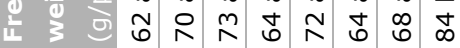

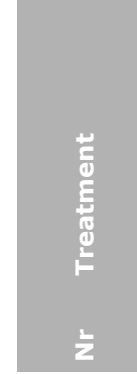

$$
\text { 《ᄄ }
$$

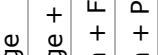

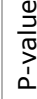

홍

v $\simeq$ o

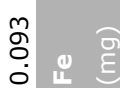

客
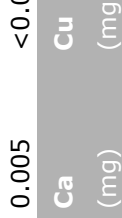

$\stackrel{\circ}{\circ}$

$\circ$

¿̊

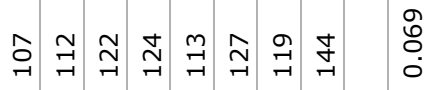

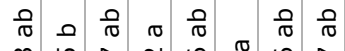

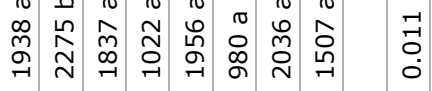

褔

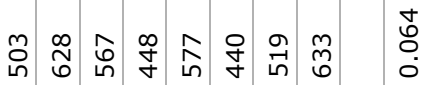

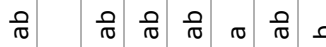

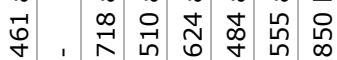

$\underset{0}{\dot{0}}$

ก

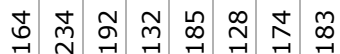

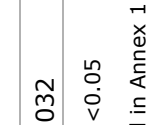

:

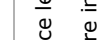

余苞

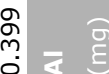

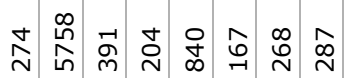

$\stackrel{n}{\rightarrow}$

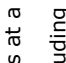

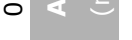

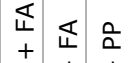

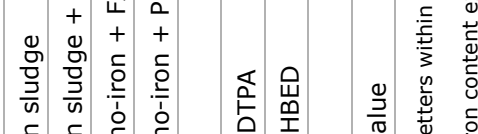

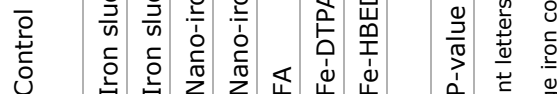

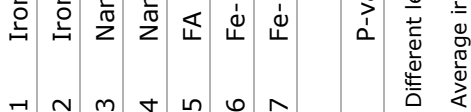




\subsubsection{Soil analyses}

Table 3.8 shows the results of the soil analyses after the pot experiment, averaged over the three replicates. Raw data are given in Table A4 (Annex 1 ).

The $\mathrm{CaCl}_{2}$ extractable iron contents were below the detection limit of $2 \mathrm{mg} / \mathrm{kg}$ in all treatments except for the Fe-HBED treatment in which $\mathrm{Fe}-\mathrm{CaCl}_{2}$ amounted to $3.3 \mathrm{mg} / \mathrm{kg}$.

In the control treatment, soil Fe-DTPA content amounted to $5.5 \mathrm{mg} / \mathrm{kg}$ which was much higher than prior to the pot experiment $(0.9 \mathrm{~g} / \mathrm{kg}$, Table 3.2). It is unknown what caused this strong increase in Fe-DTPA content during the pot experiment. It may be an effect of root exudates or of anaerobic conditions in the lower part of the pot which may in turn lead to elevated Fe(II) concentrations.

Fe-DTPA in the soil in treatments with iron sludge amounted on average to $6.3 \mathrm{~g} / \mathrm{kg}$ meaning a (not significant) $0.9 \mathrm{~g} / \mathrm{kg}$ increase compared to the control. The total iron dosage varied between $5-40 \mathrm{~g} / \mathrm{kg}$ thus only a small fraction of the added iron contributed to the build-up of DTPA-extractable iron pool. A similar effect was observed for the chelated iron-fertilisers. For example, fertilisation with $5 \mathrm{mg} / \mathrm{kg}$ Fe-DTPA fertiliser did not lead to an increase in Fe-DTPA content of the soil, indicating that the added iron was transformed to other non-extractable forms during the pot trial. For Fe-HBED, half of the added Fe was still present in DTPA-extractable form.

The addition of fulvic acid, with or without iron sludge, led to a significant increase in DOC. Dissolved organic carbon concentrations increased from $150 \mathrm{mg} / \mathrm{kg}$ to $265-425 \mathrm{mg} / \mathrm{kg}$ after addition of fulvic acids in a dosage of 318 (P2) or 528 (P3,P4) mg TOC/kg of soil. Thus, seven weeks after application, about $36-52 \%$ of the TOC added was still present in a readily soluble form.

Treatments with fulvic acid or iron sludge plus fulvic acid (P2, P3, P5) had a higher orthophosphate concentration in the $1 \mathrm{mM} \mathrm{CaCl} 2$ soil extract as compared to the control treatment and other treatments without fulvic acid. This effect was statistically significant.

Sodium concentrations were higher in treatments with fulvic acid (P2, P3, P5) which can be explained by the high sodium content of the fulvic acid product. Application of Fe-DTPA led to an increase in concentrations of copper and zinc in the soil extract whereas this effect was not observed for treatments with Fe-HBED or fulvic acid.

Table 3.8 Soil analyses, including pore water analyses $(\mathrm{mg} / \mathrm{L})$ and DTPA and $1 \mathrm{mM} \mathrm{CaCl} \mathrm{C}_{2}$ soil extractions $(\mathrm{mg} / \mathrm{kg})$, on Canaveralejo soil at the end of the growing experiment

\begin{tabular}{|c|c|c|c|c|c|c|c|c|c|c|c|c|c|c|}
\hline \multirow[b]{2}{*}{$\mathrm{Nr}$} & \multirow[b]{2}{*}{ Treatment } & \multirow{2}{*}{$\begin{array}{l}\text { Pore water } \\
\text { Fe } \\
(\mathrm{mg} / \mathrm{L})\end{array}$} & \multirow{2}{*}{$\begin{array}{l}\text { DTPA } \\
\text { Fe } \\
(\mathrm{mg} / \mathrm{kg})\end{array}$} & \multicolumn{2}{|c|}{$1 \mathrm{mM} \mathrm{CaCl}_{2}$} & \multirow[b]{2}{*}{$\mathrm{Na}$} & \multirow[b]{2}{*}{ K } & \multirow[b]{2}{*}{ Mg } & \multirow[b]{2}{*}{$\mathrm{Cu}$} & \multirow[b]{2}{*}{$\mathrm{Zn}$} & \multirow[b]{2}{*}{ DOC } & \multirow[b]{2}{*}{$\mathrm{NH}_{4}$} & \multirow[b]{2}{*}{$\mathrm{NO}_{3}$} & \multirow[b]{2}{*}{$\begin{array}{l}\text { pH } \\
(-)\end{array}$} \\
\hline & & & & $\begin{array}{l}\mathrm{Fe} \\
(\mathrm{mg} /\end{array}$ & $\begin{array}{l}{\mathrm{P}-P O_{4}} \\
/ \mathrm{kg})\end{array}$ & & & & & & & & & \\
\hline P1 & Iron sludge & $0.1^{a}$ & $6.3^{\mathrm{ab}}$ & $<2$ & $18^{a}$ & $53^{a}$ & 451 & 77 & $0.7^{a}$ & $<0.3^{a}$ & $163^{a}$ & 3 & 101 & 8.0 \\
\hline $\mathrm{P} 2$ & Iron sludge + FA & $0.1^{\mathrm{a}}$ & $6.1^{\mathrm{ab}}$ & $<2$ & $25^{\mathrm{b}}$ & $106^{\mathrm{ab}}$ & 436 & 70 & $0.8^{\mathrm{ab}}$ & $<0.3^{a}$ & $265^{a b}$ & 3 & 92 & 8.0 \\
\hline P4 & Nano-iron + PP & $0.1^{\mathrm{a}}$ & $6.2^{\mathrm{ab}}$ & $<2$ & $23^{a b}$ & $74^{\mathrm{a}}$ & 431 & 69 & $0.6^{\mathrm{ab}}$ & $<0.3^{a}$ & $150^{\mathrm{a}}$ & 3 & 92 & 8.1 \\
\hline P5 & FA & $0.1^{\mathrm{a}}$ & $5.6^{a}$ & $<2$ & $31^{c}$ & $155^{\mathrm{bc}}$ & 473 & 74 & $0.8^{\mathrm{ab}}$ & $<0.3^{a}$ & $332^{\mathrm{bc}}$ & 3 & 128 & 8.0 \\
\hline P6 & Fe-DTPA & $0.1^{\mathrm{a}}$ & $5.5^{\mathrm{a}}$ & $<2$ & $18^{a}$ & $59^{a}$ & 524 & 93 & $2.5^{c}$ & $1.9^{b}$ & $179^{a}$ & 3 & 203 & 8.0 \\
\hline P7 & Fe-HBED & $4.6^{\mathrm{b}}$ & $7.4^{\mathrm{b}}$ & 3.3 & $20^{\mathrm{ab}}$ & $61^{a}$ & 510 & 89 & $1.0^{\mathrm{b}}$ & $<0.3^{a}$ & $200^{a}$ & 3 & 152 & 8.0 \\
\hline
\end{tabular}




\subsection{Discussion}

\section{Effectiveness of iron products on iron availability in soil and on prevention of chlorosis in soybean}

This study investigated the effectiveness of iron sludge with or without fulvic acid on the prevention of iron chlorosis in soybean. It was also tested if separation of the smallest nano-sized iron particles through addition of the disperging agents fulvic acid or pyrophosphate, followed by centrifugation, provided a product with a higher Fe availability. Iron availability of the iron sludge-based products was assessed using a DTPA extraction; this showed that extractable iron increased in the order of: iron sludge (3\%); iron sludge plus fulvic acid (17\%); nano-iron plus fulvic acid (50\%). For nano-iron stabilised by pyrophosphate, only $11 \%$ of the iron was extractable by DTPA. This showed that fulvic acid substantially increased the DPTA-extractable fraction of Fe-sludge which is most likely due to dispersion. It is known that the addition of fulvic acid to iron sludge leads to a release of nano-sized iron particles that can pass a $0.45 \mu \mathrm{m}$ membrane filter. This phenomenon was previously demonstrated by assessing iron sludge solubility in water extracts with or without fulvic acid (Regelink et al. 2018) and the same mechanism is likely to explain the observed increase in DTPA-extractable iron after addition of fulvic acid to iron sludge.

The effectiveness of iron sludge as iron fertiliser was tested in two pot experiments using a loamy clay soil from Tricht (Netherlands) and a calcareous soil from Canaveralejo (Spain). Treatments included iron sludge, iron sludge plus FA, nano-iron plus FA, and nano-iron plus pyrophosphate (only in Canaveralejo soil). Two chelated iron fertilisers (Fe-HBED and Fe-DTPA) and FA (no iron) were included as a reference. The total iron dosage amount to $5 \mathrm{mg} / \mathrm{kg}$ for the synthetic iron fertilisers. Treatments with nano-iron plus FA received $10 \mathrm{mg} / \mathrm{kg}$ iron whereas treatments with iron sludge and iron sludge plus FA received 30 and $40 \mathrm{mg} / \mathrm{kg}$ iron. In doing so, differences in the percentage of DTPA extractable iron in the products, which was assumed to be an indicator for the potentially available iron, were mostly corrected for. The control treatment received all nutrients except iron. The selected soybean species was known to be susceptible to iron chlorosis and had been used in previous studies with synthetic iron fertilisers (Schenkeveld et al., 2010, Bin et al., 2016).

Soybean plants grown on Tricht soil did not show any symptoms of iron chlorosis during the pot experiment and hence, the results could not be used to draw conclusions about the effectiveness of iron fertilisers on prevention of symptoms of iron chlorosis. This absence of iron chlorosis can be explained by the fact that the Fe-DTPA content of the soil $(40 \mathrm{mg} / \mathrm{kg}$ ) was far above the threshold for iron deficient soil ( $<5 \mathrm{mg} / \mathrm{kg}$, Lindsay et al., 1978) meaning that soil was not iron deficient. This soil was chosen because pears grown on this soil showed symptoms of iron chlorosis. Apparently, the poor ability of pear to take up iron from this soil is due to other factors.

Soybean plants in the control treatment on the Canaveralejo soil showed severe symptoms of iron chlorosis during the first four weeks after sowing. These symptoms, as quantified in terms of the number of yellowish leaves, were less severe in treatments with iron sludge based fertilisers and absent in the Fe-HBED treatment. Dry matter yield increased with 30\% upon treatment with iron sludge based products (iron sludge, iron sludge plus FA, or nano-iron plus FA). Treatment with FeHBED was more effective and led to a $50 \%$ increase in dry matter yield compared to the control. The Fe-DTPA fertiliser could not prevent iron chlorosis. Fulvic acid without iron showed less symptoms of iron chlorosis as compared to the control, but dry matter yield was not improved.

Measurements of iron in soybean plants were unfortunately unreliable, probably due to contamination of plant material with dust or soil particles. In following experiments, plants must be washed with demineralised water prior to destruction in order to remove soil particles.

Soil analyses revealed that the underlying mechanisms through which iron sludge-based fertilisers affect iron uptake, differ from those of Fe-HBED fertilisers. Fertilisation with Fe-HBED led, in both soils, to a significant increase in iron concentrations in pore water samples and in the $\mathrm{CaCl}_{2}$ soil extracts. This effect was not observed in the Fe-DTPA treatments which is due to the fact that the Fe-DTPA chelate is unstable at $\mathrm{pH}$ values above 5. Neither were iron sludge-based fertilisers capable of increasing iron 
concentrations in pore water or $\mathrm{CaCl}_{2}$ soil extracts. Nevertheless, soybean plants grown on Canaveralejo soil were capable of using part of the iron supplied with the iron sludge-based products.

Another indicator for iron availability is the soil Fe-DTPA content. Iron sludge-based fertilisers were found to increase the Fe-DTPA content of the soil with 0.9 and $2.1 \mathrm{mg} / \mathrm{kg}$ in the Canaveralejo and Tricht soil, respectively. The soil Fe-DTPA content was similar for all treatments with iron sludge-based products regardless of differences in total and Fe-DTPA extractable iron added to the soil in the form of iron sludge-based fertilisers. Overall, between $7-21 \%$ and $2-8 \%$ of the added iron could be retrieved in the DTPA extract of the Tricht and Canaveralejo soil, respectively. A similar effect was found for the Fe-HBED treatments in which $40 \%$ of the added iron was detected in the soil Fe-DTPA pool at the end of the pot experiment. Hence, it seems that part of the added iron is transformed in the soil into other Fe-species insoluble in DTPA.

The amount of amorphous iron hydroxides in soil, as assessed through extraction with oxalate, is very low for the Canaveralejo soil (iron-oxalate; $0.1 \mathrm{~g} / \mathrm{kg}$ ). Such a low iron content is typical for alkaline soils in which weathering of soil minerals is inhibited due to the high $\mathrm{pH}$. Iron sludge can be used to increase the iron-oxalate content of the soil. In our pot experiment, the iron sludge dosage amounted

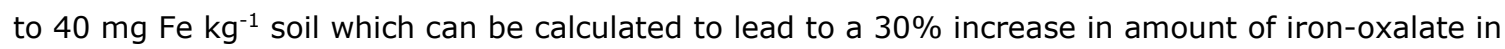
the Canaveralejo soil. This reasoning is not valid for the Tricht soil that has an iron-oxalate content of $1.7 \mathrm{~g} \mathrm{~kg}^{-1}$ which is within the expected range for soils from The Netherlands. For this soil, the iron sludge application does not affect the iron-oxalate content in the soil.

The various products also differ with respect to the method of application to soil. Synthetic iron chelates are water-soluble and can therefore be easily added to a nutrient solution and fed into the fertigation system. Similar, the nano-iron plus FA can be considered as a solution since the nano-sized particles are stabilized by fulvic acid and larger particles have been removed through centrifugation. In contrast, iron sludge and iron sludge plus FA are suspensions and their application in the field requires a dosing technique in which the product is continuously stirred in order to ensure a homogeneous distribution among the field.

\section{Effects of fulvic acid on nutrient availability and nutrient uptake}

Fulvic and humic acids are known to possess bio-stimulating properties and to increase plant yield (Rose et al., 2014). In the pot experiment, DOC concentrations at the end of the experiment were doubled in treatments with fulvic acid. In the Tricht soil for example, DOC increased from $204 \mathrm{mg} / \mathrm{kg}$ in the control to $455 \mathrm{mg} / \mathrm{kg}$ in the fulvic acid treatment. Fulvic acids are water soluble and have a very low tendency to adsorb to mineral particles in the soil, which likely explains the strong increase in DOC seven weeks after application to soil. Humic acids, in contrast, have a high affinity for adsorption to iron hydroxide particles in soil and are thus unlikely to have such a strong effect on the DOC concentration in the soil.

Application of fulvic acid led to an increase in phosphorus availability and uptake. In the Tricht soil, phosphate concentrations in $1 \mathrm{mM} \mathrm{CaCl}$ soil extracts increased from 10 to $23 \mathrm{mg} / \mathrm{kg}$ and the phosphorus content of soybean increased from 2.6 to $3.7 \mathrm{~g} / \mathrm{kg}$. Similar in Canaveralejo soil, the soil phosphate concentration was $19 \mathrm{mg} / \mathrm{kg}$ in the control treatment, and $31 \mathrm{mg} / \mathrm{kg}$ in the fulvic acid treatment. However, in Canaveralejo soil plant uptake of phosphorus was not increased, possibly due to the already very high P status of the soil. The effect of fulvic acids on uptake of cations was nonconclusive. In Tricht soil, uptake of potassium was higher in treatments with fulvic acids. On the other hand, a higher uptake of cations was observed in the Canaveralejo soil. This included potassium, calcium, manganese and magnesium. In literature, most researchers study the effect of fulvic acids on nitrogen uptake and plant yield, whereas the effect on phosphorus uptake has received little attention (Eyheraguibel et al., 2008; Verlinden et al., 2009; Zanin et al., 2018). In our pot experiment, nitrogen uptake and plant yield were not affected by the application of fulvic acid.

In this pot experiment, fulvic acid was mixed with the soil and the fulvic acid dosage corresponded to 300-680 g TOC per kg soil. The commercially advised application rate for FulVagra amounts to 
$30-70 \mathrm{~L} / \mathrm{ha}$ for a $20 \%$ fulvic acid solution ${ }^{1}$ containing $125 \mathrm{~g} \mathrm{TOC} / \mathrm{kg}$. Assuming that the product is homogenously spread over the field and mixed with the upper $10 \mathrm{~cm}$ of the soil, this corresponds to a TOC dosage of only 3 to $9 \mathrm{mg}$ TOC per $\mathrm{kg}$ of soil. In practice, bio-stimulants are used in fertigation systems or applied in a row meaning that only a fraction of the field is treated with biostimulant. Assuming a row distance of $50 \mathrm{~cm}$, one can argue that about $20 \%$ of the field receives biostimulant. Near the plant, the TOC dosage can therefore be a factor 5 higher i.e. 15-45 mg TOC per $\mathrm{kg}$.

Nevertheless, this means that the fulvic acid dosage applied in the pot experiment was a factor 7 to 45 times higher than the application dosage as advised by the retailer. As a result, also the sodium dosage was relatively high. Sodium is present in the fulvic acid product due to the use of sodium salt in the recovery process. In the pot experiments, the highest sodium dosage amounted to $180 \mathrm{mg} / \mathrm{kg}$ soil which is higher than f.e. the sodium fertilisation advice for grassland ( $<80 \mathrm{~kg} \mathrm{Na2O/ha;}$ $20 \mathrm{mg} \mathrm{Na} / \mathrm{kg}$ ). Nevertheless, we do not expect and did not observe a negative effect of this Na dosage on plant growth in our experiment. When the products is brought to the market, the advised product dosage, and hence the sodium dosage, will probably be much lower. It was now chosen to use relatively high product dosages in an attempt to increase the differences in plant performance between treatments. Future studies should focus on the effectiveness of the iron sludge-based products at lower application rates.

\footnotetext{
1 www.humintech.de Productblad FulVagra
} 


\section{Conclusions}

This study investigated the effectiveness of iron sludge as a source of iron for soybean, susceptible for Fe chlorosis, grown on a clay soil from Tricht (Netherlands) and a calcareous soil from Canaveralejo (Spain). It was also tested if separation of the smallest nano-sized iron particles through addition of fulvic acid followed by centrifugation provided a product with a higher Fe availability. Iron availability of the iron sludge-based products was as assessed using a DTPA extraction which showed that extractable iron increased in the order of; iron sludge (3\%); iron sludge plus fulvic acid (17\%); nanoiron plus fulvic acid (50\%).

Iron sludge, with or without fulvic acid, reduced symptoms of iron chlorosis and reduced the yield loss of soybean grown of the Canaveralejo soil. Differences between the effect of various iron sludge-based products could not be elucidated. Iron sludge was however not as effective as Fe-HBED, which fully prevented symptoms of iron chlorosis in soybean. The underlying mechanism differs for both products. Iron-HBED is a water-soluble fertiliser that increases iron concentration in the soil pore water and in $1 \mathrm{mM} \mathrm{CaCl}_{2}$ soil extracts. Iron sludge, on the other hand, consists of nano- and micrometer sized particles and does not have an effect on soluble iron concentrations in soil.

In the Tricht soil, iron availability of the soil turned out to be sufficient for soybean and hence the effectiveness of the iron products on prevention of iron chlorosis could not be tested.

The addition of fulvic acid was found to have a strong effect on the soil's DOC and phosphate concentration as measured in a $1 \mathrm{mM}$ soil extract. In the Tricht soil, fulvic acid was also found to increase phosphorus uptake by soybean significantly. However, the fulvic acid application rate was substantially higher as compared to the commercially advised application rates. It is advised to repeat these plant tests with other soils to tests whether the found effects depend on soil type. 


\section{References}

Aktas, M., F. van Egmond,. 1979. Effect of nitrate nutrition on iron utilization by an Fe-efficient and an Fe-inefficient soybean cultivar. Plant and Soil 51, 257-274

Bin, L. M., Weng, L. \& Bugter, M. H. J. 2016. Effectiveness of FeEDDHA, FeEDDHMA, and FeHBED in preventing iron-deficiency chlorosis in soybean. Journal of Agricultural and Food Chemistry, 64, 8273-8281.

Bollyn, J., Nijsen, M., Baken, S., Joye, I., Waegeneers, N., Cornelis, G. \& Smolders, E. 2016. Polyphosphates and Fulvates Enhance Environmental Stability of $\mathrm{PO}<\mathrm{inf}>4</$ inf $>$-Bearing Colloidal Iron Oxyhydroxides. Journal of Agricultural and Food Chemistry, 64, 8465-8473.

Boxma, R. 1972. Bicarbonate as teh most important soil factor in lime-induced chlorosis in The Netherlands. Plant and soil, 37

Broadley, M., Brown, P., Cakmak, I., Rengel, Z. \& Zhao, F. 2012. Function of nutrients: micronutrients. Marschner's mineral nutrition of higher plants, 3, 191-248.

Colombo, C., Palumbo, G., Sellitto, V. M., Rizzardo, C., Tomasi, N., Pinton, R. \& Cesco, S. 2012. Characteristics of insoluble, high molecular weight iron-humic substances used as plant iron sources. Soil Science Society of America Journal, 76, 1246-1256.

Díaz, I., Barrón, V., del Campillo, M. C. \& Torrent, J. 2010. Testing the ability of vivianite to prevent iron deficiency in pot-grown grapevine. Scientia Horticulturae, 123, 464-468.

Díaz, I., del Campillo, M. C., Cantos, M. \& Torrent, J. 2009. Iron deficiency symptoms in grapevine as affected by the iron oxide and carbonate contents of model substrates. Plant and Soil, 322, $293-302$.

Eyheraguibel, B., Silvestre, J. \& Morard, P. 2008. Effects of humic substances derived from organic waste enhancement on the growth and mineral nutrition of maize. Bioresour Technol, 99, 4206-4212.

Green, R. L., Hartwig, R. C., Richie, W. E., Loeppert, R. H. \& Beard, J. B. 1998. A selection procedure for iron-deficiency stress tolerance among warm-season turfgrasses using ferrihydrite-amended growth media. HortScience, 33, 841-844.

Houba, V. J. G., Van der Lee, J. J. \& Novozamsky, I. 1997. Soil and Plant Analysis, Part 5B: Soil analysis procedures., Wageningen University: Wageningen, The Netherlands.

Lindsay, W. L. \& Norvell, W. A. 1978. Development of a DTPA soil test for zinc, iron, manganese, and copper. Soil Science Society of America Journal, 42, 421-428.

Murphy, J. \& Riley, J. P. 1962. A modified single solution method for the determination of phosphate in natural waters. Analytica chimica acta, 27, 31-36.

Pinton, R., Cesco, S, Santi, S, Agnolon, F, Varanini, Z 1999. Water-extractable humic substances enhance iron deficiency responses by Fe-deficient cucumber plants. Plant and Soil, 210, 145-157.

Pinton, R., Cesco, S., De Nobili, M., Santi, S., Varanini Z., 1998. Water- and pyrophosphateextractable humic substances fractions as a source of iron for Fe-deficient cucumber plants. Biol. Fertil. Soils. 26

Regelink, I.C., Rietra, R., Comans, R.N.J. 2018. Gebruik van ijzerwater en fulvozuur als ijzermeststof laboratoriumtesten. Wageningen Environmental Research, Rapport 2875.

Rosado, R., Del Campillo, M. C., Martínez, M. A., Barrón, V. \& Torrent, J. 2002. Long-term effectiveness of vivianite in reducing iron chlorosis in olive trees. Plant and Soil, 241, 139-144.

Rose, M. T., Patti, A. F., Little, K. R., Brown, A. L., Jackson, W. R. \& Cavagnaro, T. R. 2014. A MetaAnalysis and Review of Plant-Growth Response to Humic Substances. 124, 37-89.

Schenkeveld, W. D. C., Dijcker, R., Reichwein, A. M., Temminghoff, E. J. M. \& van Riemsdijk, W. H. 2008. The effectiveness of soil-applied FeEDDHA treatments in preventing iron chlorosis in soybean as a function of the o,o-FeEDDHA content. Plant and Soil, 303, 161-176.

Schenkeveld, W. D. C., Temminghoff, E. J. M., Reichwein, A. M. \& van Riemsdijk, W. H. 2010. FeEDDHA-facilitated Fe uptake in relation to the behaviour of FeEDDHA components in the soilplant system as a function of time and dosage. Plant and Soil, 332, 69-85.

Schenkeveld, W.D.C., Reichwein, A.M., Temminghoff, E.J.M., Riemsdijk, van W.H. 2012. The effect of soil parameters on the kinetics of the displacement of Fe from FeEDDHA chelates by $\mathrm{Cu}$. The Journal of Physical Chemistry Part A 116, 6554. 
Schwertmann, U. 1964. Differenzierung der Eisenoxide des Bodens durch Extraktion mit Ammoniumoxalat-Lösung. Journal of Plant Nutrition and Soil Science, 105, 194-202.

van Zomeren, A. \& Comans, R. N. 2007. Measurement of humic and fulvic acid concentrations and dissolution properties by a rapid batch procedure. Environ Sci Technol, 41, 6755-6761.

Vega, V., Hidalgo, J.-C., Pariente, N., Martín, L. \& Pastor, M. 2008. Corrección de la clorosis férrica en olivar mediante el empleo de quelatos de hierro. Evaluación agronómica y económica de la aplicación de 0-0 Fe-EDDHA en secano y regadío. Vida rural, 15, 16-23.

Vempati, R. K. \& Loeppert, R. H. 1986. Synthetic ferrihydrite as a potential iron amendment in calcareous soils. Journal of Plant Nutrition, 9, 1039-1052.

Verlinden, G., Pycke, B., Mertens, J., Debersaques, F., Verheyen, K., Baert, G., Bries, J. \& Haesaert, G. 2009. Application of Humic Substances Results in Consistent Increases in Crop Yield and Nutrient Uptake. Journal of Plant Nutrition, 32, 1407-1426.

Zanin, L., Tomasi, N., Zamboni, A., Sega, D., Varanini, Z. \& Pinton, R. 2018. Water-extractable humic substances speed up transcriptional reponse of maize roots to nitrate. Environmental and Experimental Botany, 147, 167-178. 


\section{Annex 1 Raw data soil and plant analyses}

Table A1 Yield and nutrient content of soybean plant grown on the Tricht soil, 7.5 weeks after sowing

\begin{tabular}{|c|c|c|c|c|c|c|c|c|c|}
\hline $\mathrm{Nr}$ & Treatment & $\begin{array}{l}\text { Yield } \\
\text { (g/pot) }\end{array}$ & $\begin{array}{l}\text { Dry yield } \\
\text { (g/pot) }\end{array}$ & $\begin{array}{l}\mathrm{Cu} \\
(\mathrm{mg} / \mathrm{kg})\end{array}$ & $\begin{array}{l}\mathrm{Fe} \\
(\mathrm{mg} / \mathrm{kg})\end{array}$ & $\begin{array}{l}\mathrm{K} \\
(\mathrm{g} / \mathrm{kg})\end{array}$ & $\begin{array}{l}\text { Mn } \\
(\mathrm{mg} / \mathrm{kg})\end{array}$ & $\begin{array}{l}P \\
(g / k g)\end{array}$ & $\begin{array}{l}\text { Zn } \\
(\mathrm{mg} / \mathrm{kg})\end{array}$ \\
\hline 1 & Iron sludge & 154 & 42 & 8.2 & 55 & 17.4 & 59 & 2.48 & 27 \\
\hline 2 & Iron sludge & 164 & 44 & 8.7 & 46 & 18.2 & 50 & 2.65 & 29 \\
\hline 3 & Iron sludge & 170 & 45 & 8.3 & 66 & 16.9 & 61 & 2.45 & 30 \\
\hline 4 & Iron sludge + FA & 166 & 45 & 7.8 & 46 & 18.9 & 59 & 3.09 & 28 \\
\hline 5 & Iron sludge + FA & 157 & 41 & 9.2 & 44 & 20.4 & 62 & 3.76 & 34 \\
\hline 6 & Iron sludge + FA & 164 & 42 & 8.2 & 46 & 20.6 & 55 & 3.18 & 26 \\
\hline 7 & Nano-iron + FA & 168 & 45 & 8.6 & 44 & 20.7 & 61 & 3.65 & 34 \\
\hline 8 & Nano-iron + FA & 172 & 47 & 8.7 & 39 & 20.6 & 50 & 3.49 & 28 \\
\hline 9 & Nano-iron + FA & 164 & 43 & 9 & 44 & 20.5 & 69 & 3.69 & 35 \\
\hline 10 & FA & 177 & 45 & 8.1 & 47 & 20.4 & 65 & 3.32 & 28 \\
\hline 11 & FA & 156 & 41 & 8.6 & 39 & 20.7 & 62 & 3.86 & 33 \\
\hline 12 & FA & 151 & 39 & 8.8 & 42 & 22.8 & 61 & 3.77 & 30 \\
\hline 13 & Fe-DTPA & 158 & 41 & 8.7 & 53 & 18.8 & 52 & 2.65 & 48 \\
\hline 14 & Fe-DTPA & 156 & 43 & 8.9 & 46 & 18.6 & 45 & 2.71 & 45 \\
\hline 15 & Fe-DTPA & 161 & 45 & 9.6 & 59 & 17.8 & 51 & 2.68 & 48 \\
\hline 16 & Fe-HBED & 179 & 50 & 7.6 & 59 & 18.1 & 33 & 2.64 & 27 \\
\hline 17 & Fe-HBED & 158 & 44 & 8.1 & 59 & 18.2 & 34 & 2.68 & 27 \\
\hline 18 & Fe-HBED & 166 & 45 & 8.2 & 60 & 18.0 & 34 & 2.58 & 27 \\
\hline 19 & Control & 173 & 48 & 8.2 & 57 & 17.3 & 65 & 2.51 & 27 \\
\hline 20 & Control & 158 & 42 & 8.7 & 55 & 19.0 & 57 & 2.69 & 26 \\
\hline 21 & Control & 141 & 37 & 8.7 & 54 & 21.6 & 67 & 2.76 & 26 \\
\hline
\end{tabular}


Table A2 Soil characteristics at the end of the pot experiment with soybean on the Tricht soil in $\mathrm{mg} / \mathrm{kg}$ soil except for Fe-pore water which is in $\mathrm{mg} / \mathrm{L}$

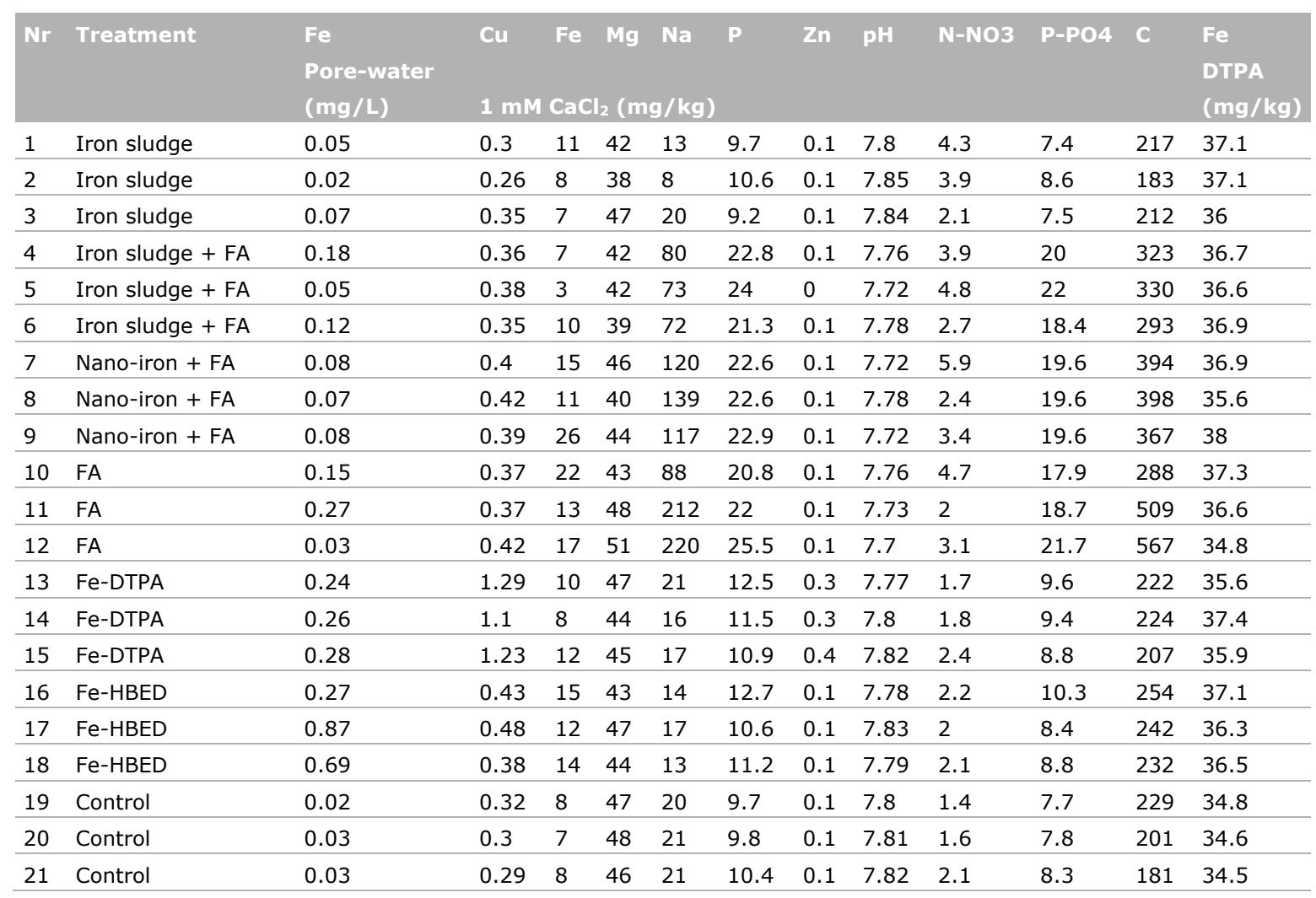




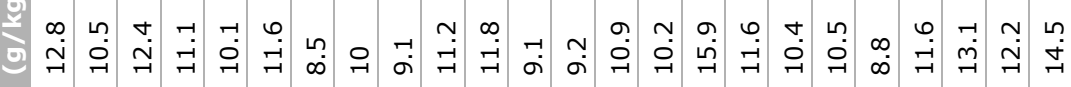

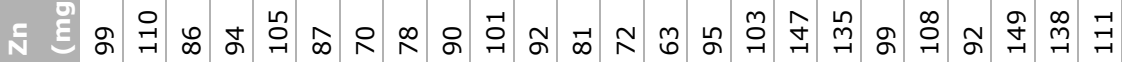

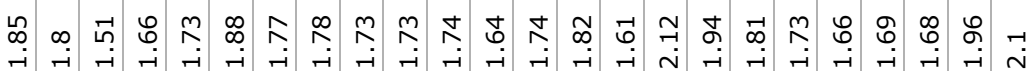

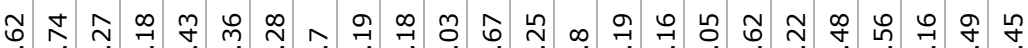

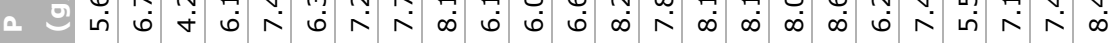

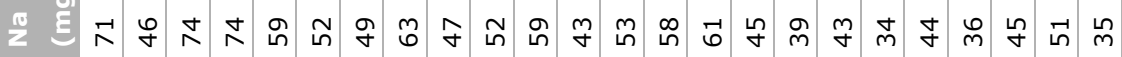

일

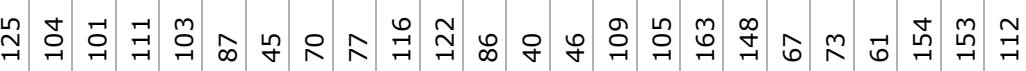

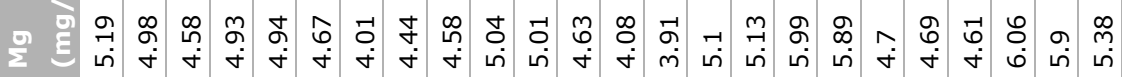

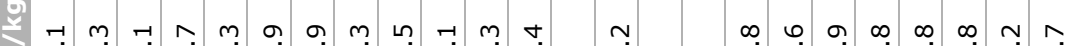
₹ 일

ì

बำ

iiv $\stackrel{0}{\pi}$

का उ

క

के

$\frac{\sqrt{0}}{\stackrel{0}{2}}$

$\frac{1}{5}$

ఖ 


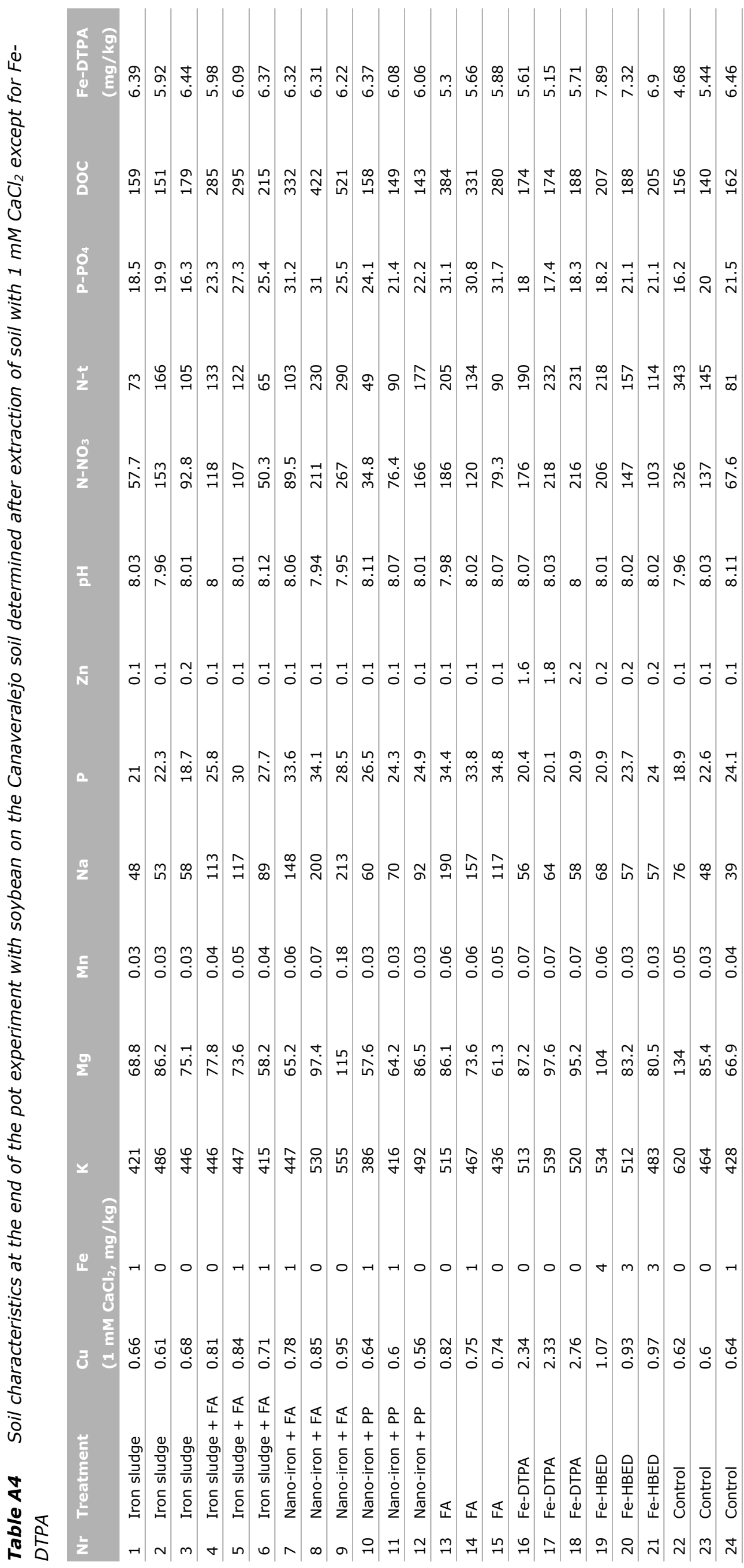


Wageningen Environmental Research P.O. Box 47

6700 AA Wageningen

The Netherlands

T +31 (0)317480700

www.wur.nl/environmental-research

Wageningen Environmental Research Report 2971

ISSN 1566-7197
The mission of Wageningen University \& Research is "To explore the potential of nature to improve the quality of life". Under the banner Wageningen University \& Research, Wageningen University and the specialised research institutes of the Wageningen Research Foundation have joined forces in contributing to finding solutions to important questions in the domain of healthy food and living environment. With its roughly 30 branches, 5,000 employees and 10,000 students, Wageningen University \& Research is one of the leading organisations in its domain. The unique Wageningen approach lies in its integrated approach to issues and the collaboration between different disciplines.

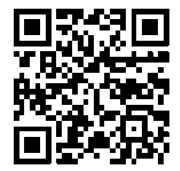





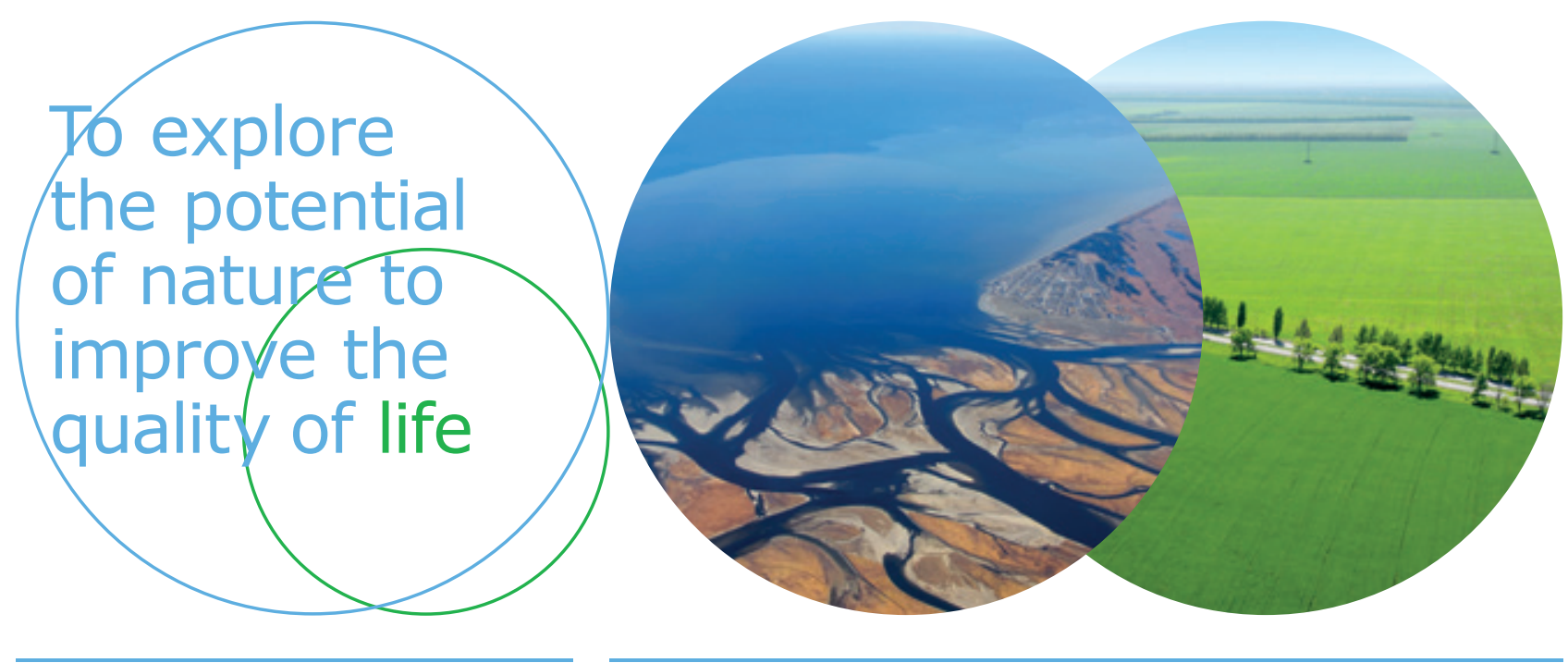

Wageningen Environmental Research P.O. Box 47

$6700 \mathrm{AB}$ Wageningen

The Netherlands

$T+31(0) 317480700$

www.wur.eu/environmental-research

Report 2971

ISSN 1566-7197
The mission of Wageningen University \& Research is "To explore the potential of nature to improve the quality of life". Under the banner Wageningen University \& Research, Wageningen University and the specialised research institutes of the Wageningen Research Foundation have joined forces in contributing to inding solutions to important questions in the domain of healthy food and living environment. With its roughly 30 branches, 5,000 employees and 10,000 students, Wageningen University \& Research is one of the leading organisations in its domain. The unique Wageningen approach lies in its integrated approach to issues and the collaboration between different disciplines. 